\title{
Investigation of slug-churn flow induced transient excitation forces at pipe bend.
}

HOSSAIN, M., CHINENYE-KANU, N.M., DROUBI, G.M., ISLAM, S.Z. 


\title{
Investigation of Slug-Churn Flow Induced Transient Excitation Forces at Pipe Bend
}

Mamdud Hossain*, Nkemjika Mirian Chinenye-Kanu, Ghazi Mohamad

Droubi and Sheikh Zahidul Islam

School of Engineering, Robert Gordon University, Sir Ian Wood Building, Garthdee Road, Aberdeen, AB10 7GJ, UK

*Corresponding Author. Email: M.Hossain@rgu.ac.uk, Phone: +44 (0)1224 262351, Fax: +44(0)1224262444

\begin{abstract}
Numerical simulations of two-phase flow induced fluctuating forces at a pipe bend have been carried out to study the characteristics of multiphase flow induced vibration (FIV). The multiphase flow patterns and turbulence were modelled using the volume of fluid (VOF) method and the $k-\epsilon$ turbulence model respectively. Simulations of seventeen cases of slug and churn flows have been carried out showing the effects of superficial gas and superficial liquid velocities. The simulations results show good agreement of the volume fraction fluctuation frequencies of slug and churn flows with the reported experiment. In addition, the vibration characteristics of the excitation force have been accurately captured. The simulation results show that the predominant frequency of fluctuations of force decreases and the RMS of force fluctuation increases with the increase of superficial gas velocity. On the other hand, both predominant frequency and the RMS of force fluctuations increases with the increase of superficial liquid velocity. Increase of gas fraction narrows the range of frequency ranges, while increasing the liquid expands the frequency ranges of force fluctuations.
\end{abstract}

Keywords: Flow induced vibration; numerical modelling; pipe bend; slug/churn flow; force fluctuations 


\section{Introduction:}

Knowledge of two-phase flow induced vibration (FIV) due to internal flowing fluid along with its fluctuating forces and predominant frequencies has become increasingly important in several engineering applications including chemical process systems, oil and gas flowlines, and nuclear energy generation systems (1). FIV can be disruptive to engineering systems during operations and can cause serious failures to engineering systems including fatigue failure, resonance and structural wear $(2,3)$. Therefore, the prediction of flow induced forces and their interactions with its structures is crucial at both design and operating stages of process piping systems. Majority of the studies of FIV have considered random turbulence excitation (4), acoustic resonance and vortex shedding (5) in single-phase flows. Multiphase flows induced vibration investigations are rare. Unlike the single-phase flows, FIV in multiphase flows is more difficult to analyse and characterise due to the complex phase interactions as well as its highly unsteady and unstable nature. Initially, multiphase flow FIV was addressed for nuclear industry as a result of steam-water flow system (6). One of the challenges of understanding the Multiphase FIV is that it is flow regime specific. It has been shown that the slug and churn-turbulent flow patterns are the sources of the most significant dynamic forcing functions compared to other flow regimes (7-14). These flow patterns are inherent in subsea and onshore flowlines and hydrocarbon process systems. They have been recorded to cause FIV related interruptions in oil and gas operations (15 17). Hence, accurate models and correlations are required to proactively address the multiphase FIV and pipeline integrity challenges. This is even more important as multiphase FIV can occur in difficult environment such as offshore platform

A number of experimental studies have been reported and some correlations to predict multiphase flow induced force characteristics have been developed. Yih and Griffith (6) investigated the two-phase flows through a vertical duct impacting on a beam structure and studied the 
momentum flux fluctuations. They investigated flows with a velocity range of $15-75 \mathrm{~m} / \mathrm{s}$, duct diameters of $6.35 \mathrm{~mm}, 15.9 \mathrm{~mm}$ and $25.4 \mathrm{~mm}$, with volume fraction of gas of $50-100 \%$. Their key findings were that the maximum void fraction fluctuations are high in slug and annular flows and the predominant fluctuation frequency were less than $30 \mathrm{~Hz}$.

Tay and Thorpe (9) carried out experiments to study the effects of density, viscosity and surface tension of liquid on slug flow induced forces on a horizontal $90^{\circ}$ pipe bend. The pipe internal diameter was $70 \mathrm{~mm}$ and the gas and liquid superficial velocities were $0.38-2.87 \mathrm{~m} / \mathrm{s}$ and $0.2-0.7 \mathrm{~m} / \mathrm{s}$ respectively. The piston flow model (PFM) developed in the study over predicted the maximum resultant forces more significantly for gas superficial velocities above $2.5 \mathrm{~m} / \mathrm{s}$. The square root of the maximum resultant force predicted with PFM showed a linear relationship with mixture velocity. The study also concluded that no significant effect of liquid physical properties was observed on the force characteristics.

Riverin et al. (10) studied the FIV in a pipe diameter of $20.6 \mathrm{~mm}$ with a $\mathrm{U}$-bend and a T-junction. They have investigated 11 test cases within the gas volume fraction $50 \%$ and $75 \%$ and the mixture velocities of $2-12 \mathrm{~m} / \mathrm{s}$. For both volumetric qualities and geometries, the predominant frequency of force fluctuations were reported to increase from approximately $2 \mathrm{~Hz}$ to $30 \mathrm{~Hz}$ with increasing mixture velocities. The root mean squares of the equivalent bend forces were observed to be between $1-12 \mathrm{~N}$, . Riverin et al. (10) developed a correlation of the dependence of dimensionless RMS force on Weber number based on their experimental data and the previously reported data of Yih and Griffith (6) and Tay and Thorpe (9).

Cargnelutti et al. (11) investigated the stratified, slug and annular flows in pipes of internal diameters of $25.4 \mathrm{~mm}$ in a horizontal orientation. The gas and liquid superficial velocities ranged from 0.1 to $30 \mathrm{~m} / \mathrm{s}$ and 0.05 to 2 $\mathrm{m} / \mathrm{s}$ respectively. Forces were measured for straight pipe, T-joint, T-joint with one of the arms closed off ( $T$-bend), $90^{\circ}$ sharp bend and large radius bend. The measured dimensionless slug flow induced forces in the bend and T-bend agreed well with the values predicted by Riverin et al. (10)'s model. However, the stratified and annular flows data did not conform well with 
Riverin et al (10) model. Further, Cargnelutti (11) proposed a simple analytical model based on the momentum change due to the slug flow to calculate the resultant force at a bend. The model performed better for slug flows compared to annular and stratified flow. The model was modified to be based on the mixture velocity so that the model would predict the annular and stratified flow induced forces.

Riverin and Pettigrew (12) extended the experimental study of Riverin et al (10) on a pipe diameter of $20.6 \mathrm{~mm}$ to four vertical bend configurations of $R / D=0.5,2,5$ and 7.2 and volumetric qualities of 25, 50, 75 and 95\% corresponding to mixture velocities from $1 \mathrm{~m} / \mathrm{s}$ to $20 \mathrm{~m} / \mathrm{s}$. Their study shows that the predominant frequencies and root mean squares of forces (Frms) matched the previously developed correlation of Riverin et al. (10).

More recently, Liu et al. (13) and Miwa et al.(14) conducted experimental studies in flow induced vibration (FIV) in vertical and horizontal (18) $90^{\circ}$ bends of $52.5 \mathrm{~mm}$ diameter pipe with a radius of bend of $76.2 \mathrm{~mm}(13,14)$. 36 multiphase flow cases of flows encompassing bubbly, slug, churn and annular flow regimes were investigated in the vertical bend. Gas and liquid superficial velocities were in the range of $0.1-18 \mathrm{~m} / \mathrm{s}$ and $0.61-2.31 \mathrm{~m} / \mathrm{s}$ respectively. The horizontal and vertical components of RMS of forces for all the slug and churn flow were reported to be within 2-60 N. The corresponding force frequencies were in the range of $1-7 \mathrm{~Hz}$ and $1-11 \mathrm{~Hz}$, respectively. In the slug flow, the experimental values for the maximum magnitude of force fluctuation was approximately $5 \mathrm{~N}$ while the predominant frequency was approximately $8 \mathrm{~Hz}$. The corresponding values for the churn flow were approximately $6 \mathrm{~N}$ and $3 \mathrm{~Hz}$, respectively. They have developed an analytical model to study the frequency of force fluctuations based on a two-fluid model. In (14), the developed model included an impact force term, which performed better in predicting force fluctuations frequency compared to the previous model without the term. The accuracy of the force frequency model were reported to be approximately $30 \%$ and $25 \%$ respectively in two studies as reported in (14) and (18). 
In parallel to experimental studies, CFD technique has been used for FIV studies. Application of CFD modelling for FIV study is inherently challenging as the methodology needs to be robust to tackle interfaces of different multiphase flow regimes as well as turbulence characteristics. Several models have been developed for tackling multiphase flow regimes such as volume of fluid (VOF), two-fluid Eulerian and Mixture models. The VOF model tracks the interface between phases and is more suitable for stratified, slug or churn flow modelling. One the other hand, two-fluid Eulerian model treats each phase separately solving individual continuity and momentum equations. The phase are coupled through sub-models specific to each flow regime. A less computationally expensive mixture model combines the phases into a single mixture solving a single set of continuity and momentum equations. In this modelling approach, a transport equation for the secondary phase is solved and phase interactions are treated using the slip velocities, which depend on the flow regime. Both two-Fluid Eulerian and Mixture model are suitable for modelling dispersed bubble flows. Another model suitable for dispersed bubble or droplet flows is Lagrangian particle tracking, where each individual particle is tracked through the carrier fluid. This method is computationally expensive specially coupled with the stochastic turbulence model. Some specialised multiphase models are also available to combine the large interface flows such as slug with dispersed bubbles or large bubbles with smaller bubbles using Ishii's model or the Multifluid-VOF. Another challenge of modelling of multiphase flows is the accurate treatment of the effects of turbulence. Direct Numerical Simulation (DNS) resolves turbulent structures at all length and time scales and thus is computationally very expensive. Large Eddy Simulation (LES) as the name suggests resolves the larger eddies, while the smaller eddies are modelled, while Reynolds Averaged Navier Stokes (RANS) models all time and length scales of turbulent structures. Though LES modelling is desirable for multi-phase flow modelling, RANS models are computationally inexpensive and with proper treatment of near walls, it has widely been used for multiphase flow modelling. 
The volume of fluid (VOF) model in computational fluid dynamics (CFD) has been reported to perform satisfactorily in slug flow (18-22) and churn turbulent flow $(23,24)$ modelling. In addition, CFD technique has shown good potentials in FIV investigations $(4,16,17,20,26-28)$. The mixture model with the transport of interfacial area concentration has been successfully utilised for the study of multi-phase flow induced vibration on the pipe bundles $[29,30]$. Ter Hofstede (4) has applied a coupling of CFD and solid mechanics modelling to study FIV in a nuclear fuel rod using single phase RANS $k-\omega$ SST and RSM models. Pontaza et al. (16) have applied CFD and FEA to investigate flow induced vibration on a subsea pipe jumper and compared the effects on Tee and Bend using LES model. Their modelling has the weakness of neglecting liquid phase volume fraction of $1.5 \%$ and treating the flow as single-phase. Subsequently, Pontaza et al. (17) used the CFD technique to carry out a FIV assessment of an operational subsea oil and gas manifold with a combination of bends and T-joints for a single mixture velocity with $2.2 \%$ liquid within a gas condensate using twophase flow modelling. They has resolved turbulence with LES model and the two-phase flows with VOF model. Their flow domain consisted of 8"X6" connection leading to $12^{\prime \prime}$ pipe. Force calculations were carried out on the T-joint and a vertical $6^{\prime \prime} 90^{\circ}$ bend upstream of the joint. The study reported a predominant frequency in the range of $10-40 \mathrm{~Hz}$ from the power spectral analysis of the time domain signal of the three component of forces. They also shows that including liquid phase broadens the frequency range compared to single-phase gas only flow modelling. Emmerson et al. (20) used CFD to study flow induced forces in a horizontal $180^{\circ}$ pipe bend of 4 " (101.6 mm) diameter. The VOF model was used for the two-phase flows modelling while LES was used to model turbulence to predict slug flow with superficial liquid and gas velocities of $2.4 \mathrm{~m} / \mathrm{s}$ and $2.2 \mathrm{~m} / \mathrm{s}$ respectively. They also modelled a second case from Tay and Thorpe (9) experiment with superficial liquid velocity of $1.8 \mathrm{~m} / \mathrm{s}$ and superficial gas velocity of $0.5 \mathrm{~m} / \mathrm{s}$ within a $70 \mathrm{~mm}$ diameter pipe of $90^{\circ}$ bend. The RMS value of the horizontalcomponent of force obtained from CFD was $137.3 \mathrm{~N}$ compared to their own experimental value of $131.1 \mathrm{~N}$. Power spectral analysis of the time domain signal of forces gave predominant frequencies in the range of $0-5 \mathrm{~Hz}$ (1 $\mathrm{Hz}$ peak) and $0.5-10 \mathrm{~Hz}(1.8 \mathrm{~Hz}$ peak) for the CFD and experimental 
method respectively. The RMS value of the vertical components of forces obtained with CFD of $22 \mathrm{~N}$ did not match with the experimental value of 59.4 N. However, their simulation of Tay and Thorpe (9) shows good prediction of peak force frequency and average resultant force. Zhu et el. $(27,28)$ simulated flow included pipe deflection using single-phase CFD analysis.

Further CFD analyses has been carried out for FIV by Montoya-Hernandez et al. (31) in large diameter pipe using a simplified one-dimensional homogeneous flow models with turbulence treated with wall shear stress. There studies show that CFD method can perform well in FIV predictions. However, Montoya-Hernandez et al. (31) assumed the multiphase flow to be a homogenously mixed single phase in their formulation. This assumption could lead to invalid conclusions if the formulation is applied to slug and churn flow patterns.

In summary, above literature review shows that the available analytical model presented in Liu et al (13) and Miwa et al (14) is capable of predicting the frequency of excitation forces within 30\% accuracy. In addition to the relatively high margin of error of the model, the proposed analytical model also requires void fraction data from experimental measurement as input to calculate impact force fluctuations term. Thus, in order to use the model to solve flow problems at both operating and design stages of practical systems, experiments have to be conducted to extract void fraction signals using the problem specific flow conditions and geometry. On the other hand, the RMS of fluctuating force could be predicted using Riverin et al (10) empirical correlation within $50-75 \%$ gas volume fraction. In this respect, CFD is a viable tool to predict both frequency and the RMS of force fluctuations with all operating ranges. Current literature on comprehensive applications of CFD for flow induced vibration study, encompassing a range of flow velocities is rather limited.

Therefore, the present study applies a CFD modelling technique to simulate flow induced fluctuating forces for a wide range of flow conditions covering slug and churn flows. Since the flow regime analysed is slug and slug-churn flows, which has clear interface, the VOF model is the most appropriate for 
treating multi-phase flows and has been utilised in the present study. Turbulence was treated with the two-equation $k-\epsilon$ model with standard wall function. In the present study, the CFD simulations of flow induced properties has been validated against the experimental data of Liu at al (13) and the empirical model of Riverin et al (10) and thus giving confidence in applying CFD for flow induced vibration problem. This paper provides an extensive data set from numerical experiment for the first time for identifying and mitigating flow induced vibration under slug and churn flow regimes.

\section{Methodology}

Computational Fluid Dynamics technique has been used in the present study to extract fluctuating flow properties due to multiphase flows. Since the focus of the study is slug and churn flow, the multiphase volume of fluid (VOF) method is utilised to track the interface between liquid and gas phases.

\subsection{Continuity, momentum and volume fraction}

In the VOF method, a single set of momentum equations is shared by phases (here, air and water) and the volume fraction of each phase is tracked through the computational domain. The governing equations for the VOF model are given below (33):

Continuity:

$$
\frac{\partial \rho}{\partial t}+\nabla \cdot(\rho \bar{u})=0
$$

Momentum:

$$
\frac{\partial(\rho \overline{\boldsymbol{u}})}{\partial \boldsymbol{t}}+\nabla \cdot(\rho \overline{\boldsymbol{u}} \overline{\boldsymbol{u}})=-\nabla \boldsymbol{P}+\nabla \cdot \boldsymbol{\mu}\left(\nabla \overline{\boldsymbol{u}}+\nabla \overline{\boldsymbol{u}}^{\boldsymbol{T}}\right)+\boldsymbol{F}
$$


The surface tension force in equation (2) is represented by $F$. The surface tension force is expressed as a volume force and is added to the momentum equation as a source term.

To track the interface between phases a volume fraction continuity equation for one of the phases (water in this case) is solved along with the above equations:

$$
\frac{\partial \alpha_{q}}{\partial t}+\vec{u} . \nabla \alpha_{q}=0
$$

where subscript $q$ represents each phase component.

Air volume fraction is obtained from the relation

$$
\sum_{q=1}^{2} \alpha_{q}=1
$$

The properties appearing in the transport equations are determined by the presence of the component phases in each control volume. For example, the density is considered to be:

$$
\rho=\sum_{q=1}^{2} \alpha_{q} \rho_{q}
$$

The surface tension effects between liquid water and air has been considered by using the continuum surface force (CSF) model. According to this model, the volume force is added to the momentum source as,

$$
F=\sigma\left(\frac{\rho k_{1} \nabla s_{1}}{1 / 2\left(\rho_{l}+\rho_{g}\right)}\right)
$$

Where, $\sigma$ is the surface tension coefficient, and $\kappa_{1}$ is the surface curvature of the liquid droplet defined in terms of the divergence of the unit normal, and is given by,

$$
k_{1}=\nabla \cdot \bar{n}_{1}
$$


The unit normal vector, $\mathrm{n}_{1}$ is calculated from the local gradients in the surface normal at the interface as,

$$
\bar{n}_{1}=\frac{\nabla s_{1}}{\left|\nabla s_{1}\right|}
$$

Wall adhesion effects are accounted for by adjusting the surface curvature near the wall, where gas-liquid interface meets the solid wall. The local curvature of this interface is determined by the contact angle, $\theta_{w}$, which represents the angle between the wall and the tangent to the interface at the wall. The surface normal vector at the wall is given by,

$$
\bar{n}=\bar{n}_{w} \cos \theta_{w}+\bar{t}_{w} \sin \theta_{w}
$$

Where, $\bar{n}_{w}$ and $\bar{t}_{w}$ are the unit vectors normal and tangential to the wall, respectively.

\subsection{Turbulence Model}

The mixture turbulence model is the simplified extension of the single phase $k-\epsilon$ model. In this model, it is deemed that the mixture properties and mixture velocities could adequately capture the main features of turbulent flow.

The mixture turbulent kinetic energy $k$ is given by (34):

$$
\nabla \cdot\left(\rho_{m} \vec{v}_{m} k\right)=\nabla \cdot\left(\frac{\mu_{t, m}}{\sigma_{k}} \nabla k\right)+G_{k, m}-\rho_{m} \epsilon
$$

The mixture energy dissipation rate $\epsilon$ is given by:

$$
\nabla \cdot\left(\rho_{m} \vec{v}_{m} \epsilon\right)=\nabla \cdot\left(\frac{\mu_{t, m}}{\sigma_{\epsilon}} \nabla \epsilon\right)+\frac{\epsilon}{k}\left(C_{1 \epsilon} G_{k, m}-C_{2 \epsilon} \rho_{m} \epsilon\right)
$$

Where, the mixture density and velocities are given by: 


$$
\rho_{m}=\sum_{i=1}^{N} \alpha_{i} \rho_{i}
$$

And

$$
\bar{v}_{m}=\frac{\sum_{i=1}^{N} \alpha_{i} \rho_{i} \bar{v}_{i}}{\sum_{i=1}^{N} \alpha_{i} \rho_{i}}
$$

The turbulent viscosity, $\mu_{t, m}$ is computed from:

$$
\mu_{t, m}=\rho_{m} C_{\mu} \frac{k^{2}}{\epsilon}
$$

And the production of turbulent kinetic energy, $G_{k, m}$ is computed from:

$$
G_{k, m}=\mu_{t, m}\left(\nabla \bar{v}_{m}+\left(\nabla \bar{v}_{m}\right)^{T}\right): \nabla \bar{v}_{m}
$$

The turbulent model constants are:

$C_{1 \epsilon}=1.44, C_{2 \epsilon}=1.92, \sigma_{k}=1.0, \sigma_{\epsilon}=1.3$

Above set of governing equations are implemented in commercial CFD software FLUENT. In the simulations, the pressure-velocity was coupled through SIMPLE scheme, pressure equation was discretised using PRESTO and interface between gas-liquid was tracked through geo-reconstruct scheme (35).

\subsection{Computational Geometry and Mesh}

The computational domain and flow conditions are similar to the experimental set-up of Liu et al. (13) which is an upward flow in vertical $90^{\circ}$ elbow of diameter $0.0525 \mathrm{~m}$ and radius of curvature of $0.0762 \mathrm{~m}$ shown in Figure 1a.

Computational domain has been divided into hexahedral mesh using ICEMCFD software. Three levels of mesh dependency test has been carried out. The meshes which were used to conduct the mesh independent study are also shown in Figure 1b. Setting up the inlet flow velocity for multiphase flows, especially for slug and churn flows, where phases are separated, is a 
challenge. One way to deal with this, would be to set an inlet mixture velocity and no-slip gas volume fraction in the inlet. Flow would eventually separate out within the flow domain, however, a very long how domain would be needed. A more efficient method of setting inlet boundary condition for slug and churn flows have been described in Parsi et al (36) and has been utilised in the present study.

In order to expedite the development of multiphase flow regimes, the inlet was split into two sections, with central core used for air flow and the surrounding annular for water flow. Fluids are introduced into the flow domain at the inlets by setting the phase velocities. The gas and liquid phase velocities are calculated respectively as:

$v_{g}=\frac{v_{s g} A}{A_{g}}$ and $v_{l}=\frac{v_{s l} A}{A_{l}}$, where $v_{g}$ and $v_{l}$ are specified gas and liquid inlet velocities, $v_{s g}$ and $v_{s l}$ are superficial gas and liquid velocities, $A$ is the crosssectional area, $A_{g}$ and $A_{l}$ are the area of gas and liquid area inlets. Though the inlet areas, $A_{g}$ and $A_{l}$ were selected arbitrarily, it is expected the particular choice of the areas and thus the inlet velocities would not affect the final outcome as the development of specific flow patterns is dependent on the superficial velocities only. The selection of inlet areas would only affect the length of the flow pipe needed before the flows to develop and to distribute themselves into specific patterns. In the present study, the inlet length is sufficiently long for flow to develop and separate into expected slug and churn flow patterns. The simulation has been carried out with a time step of 0.00001 second.

\section{Results and discussion}

Two-phase air-water flow simulations have been carried out to investigate the effects of liquid and gas velocities on excitation force characteristics at the pipe bend. In the CFD analysis, the superficial gas velocity was varied from $0.5 \mathrm{~m} / \mathrm{s}$ to $9.04 \mathrm{~m} / \mathrm{s}$, while keeping the liquid superficial velocity at $0.642 \mathrm{~m} / \mathrm{s}$ encompassing the slug to churn flow regimes. Further, the effects of liquid superficial velocity have been captured by varying the velocity from 0.642 to $5 \mathrm{~m} / \mathrm{s}$, while keeping the superficial gas velocity 
constant at $5 \mathrm{~m} / \mathrm{s}$. Figure 2 shows the simulation conditions plotted on the superficial gas and liquid velocity plane together with flow transition plot of Mishima and Ishii's [37] for upward two-phase flows. The simulation conditions mainly falls within the slug flow regimes.

\subsection{Mesh independency}

Mesh dependency test has been carried out using the three different meshes for the slug flow with superficial liquid velocity of $0.61 \mathrm{~m} / \mathrm{s}$ and superficial gas velocity of $0.978 \mathrm{~m} / \mathrm{s}$. Figure 3(a) shows that the velocity profile at $0.2 \mathrm{~m}$ upstream of the bend for all three meshes are almost similar and they represent typical velocity profile of a fully developed turbulent flow in pipe. Further, the effects of mesh size on the variation of void fraction has been shown in Figure 3(b) together with experimental data from Liu et al. (13). The figure shows that the development of flows is dependent on the mesh size and the fluctuations vary significantly among different meshes. However, mesh independency testing based on void fraction time series is quite challenging as discussed by Parsi et al (36) and thus discrepancies in void fraction fluctuations have been quantified against the average data. For this slug flow, void fraction data is available from the experiment of Liu et al. (13) at this location. In the present study, the timeaveraged mean volume fraction at this location was calculated to be 0.438 , 0.476 and 0.439 for mesh sizes of 154840, 227136 and 366912, respectively. The experimental value of Liu et al. (13) was 0.427. Figure 3 (c) shows the effects of mesh size on the predicted PSD of volume fraction. This figure shows a good agreement with experimental data using a mesh size of 366912. It is inherently difficult to predict transient phenomenon of slug flows. Thus, based on the prediction of velocity profile, void fraction and PSD of volume fraction, the mesh of size 366912 was treated as grid independent.

\subsection{Two-phase volume fraction results}

\subsubsection{Contour plots of void fraction}


Figure 4 shows the volume fraction contour plots of gas within the flow domain for different superficial gas velocity after 5 seconds of flow. The figure shows that the CFD model captures the flow features of slug, churn and churn-annular flow well. The slug is visible clearly upto superficial gas velocity of $1.7 \mathrm{~m} / \mathrm{s}$ characterised by large gas bubbles surrounded by thin liquid films and cyclic liquid structures. As expected in slug flows, gas bubbles are also entrained within the liquid structures. It should be noted that the VOF model is good at tracking large interfaces between the phases. Thus the smaller bubbles and their interactions entrained within the liquid structures are not captured in the simulation. As the superficial gas velocity increases further, (at $2.765 \mathrm{~m} / \mathrm{s}$ and $5 \mathrm{~m} / \mathrm{s}$ ), the liquid structure's integrity is lost due to the penetration of gas into the liquid at higher gas velocities and the flow is characterised by large scale liquid waves at the wall and breaking down of large gas bubbles into smaller or continuous core. This flow regime is termed churn flows. Further increase of superficial gas velocity at $9.04 \mathrm{~m} / \mathrm{s}$, the flow is almost at the boundary of churn to annular flow transition. At this velocity, the flow is characterised by gas core and discontinued liquid wavy structures at the wall. Despite the shortcoming of the VOF model to capture smaller bubbles and droplets, large scale flow features of slug and churn flows are captured well.

\subsubsection{Effects of gas velocity on area averaged void fraction}

The force fluctuations in the bend is primarily due to the momentum flux at the bend. As given in Liu et al. (13) under homogeneous flow conditions, the momentum flux in two phase-flow can be calculated as:

$M=A V_{t}^{2}\left[\rho_{g} \tilde{\alpha}_{g}^{A}(t)+\rho_{l}\left(1-\tilde{\alpha}_{g}^{A}(t)\right)\right]$

Where, $\tilde{\alpha}_{g}^{A}$ represents the area averaged void fraction and $V_{t}$ is the mixture velocity. Therefore, it is interesting to analyse the void fraction fluctuations under different flow conditions. 
The area averaged void fraction fluctuations seems to be a key parameter in flow induced vibration study (13). Figures 5 and 6 show comparison of the time domain signals and the power spectrum densities (PSD) of the void fraction obtained from the present CFD study and reported experiment (13) for a slug and churn flow respectively. The CFD prediction represents well the void fraction fluctuations of both slug and churn flows as can be seen in Figures 5(a) and 6(a), respectively. In particular, the slug flow is characterised by the liquid slug bodies with void fraction averaging around $20 \%$ and the gas bubbles with void fraction of $80 \%$. The PSD of the slug flow, Figure 5 (b), shows a peak at $2.5 \mathrm{~Hz}$ which matches well with the experimental value. Churn flow is inherently more complex to predict, however, the CFD simulation reproduced the experimental signal well as shown in Figure 6(a). As expected, the PSD (Figure 6(b)) shows a range of frequencies and similar trend as reported in the experiment (13). The most predominant frequency has been predicted to be around $0.6 \mathrm{~Hz}$. Relative to the slug flow (Figure 5 (b)), the PSD of the churn flow is smaller by an order of magnitude.

Figure 7 shows the predicted void fraction fluctuations and their power spectrum density for different flow regimes keeping the liquid velocity fixed at $0.642 \mathrm{~m} / \mathrm{s}$. The main flow features observed in these time series are as flows: (1) at lower superficial velocities (below $1.7 \mathrm{~m} / \mathrm{s}$ ), the time averaged void fraction fluctuations broadly varies between two distinct values of $80 \%$ and $20 \%$. (2) While at the higher end of the void fraction of $80 \%$, the time series is generally uniform, at the lower end of void fraction of $20 \%$, the time series shows high frequency fluctuations (3) at higher superficial velocities (above $2.765 \mathrm{~m} / \mathrm{s}$ ), the cyclic fluctuations in the time series is characterised by sudden drops of the void fraction. (4) the amplitude of the drops decreases with the increase of superficial gas velocities (5) at lower end of the superficial gas velocities $(2.765 \mathrm{~m} / \mathrm{s})$, a broad range of amplitudes in drops is observed (6) with further increases of superficial gas velocities, the drop in amplitude becomes more uniform. These observations can be interpreted as follows: at superficial gas velocities, the flow is characterised by slug flows with the transport alternative structures of gas and liquid. Gas bubbles generally has uniform structures, while the 
liquid structures often entertained gas bubbles as characterised high frequency, low amplitude vibrations at around $20 \%$ of void fraction. It should be noted though, the present VOF model can only predict the presence of larger bubbles within the liquid body. The presence of smaller bubbles and its associated fluctuations are not captured in the present study. With the increase of superficial gas velocities, the flow is transitioned to churn flows, which is characterised by the sudden drops in void fraction fluctuations. These drops indicate the passage of liquid structures. As the superficial gas velocity increases (to $9.04 \mathrm{~m} / \mathrm{s}$ ), more and more gas penetrates through the liquid structures, liquid structures lose their integrity and breaks into large wavy structures along the wall, which is at the boundary of transition from churn to slug flows.

Figures 7(a) (i) - (iii) show the consistent slug flow regimes, where the void fraction have been dominated by liquid slugs with average void fraction of around $20 \%$ and gas bubbles with void fraction of $80 \%$. The corresponding PSD in Figures 7(b) (i)- (iii) show the dominant frequency is approximately $2 \mathrm{~Hz}$, which drops slightly with the increase of gas velocity. The spread of PSD is between 0 and $10 \mathrm{~Hz}$. Figures 7(a) and (b) (iv) - (vii) show that the slug structure starts to breaks down as the gas superficial velocity increases to churn flow velocities. The PSD of churn flow is characterised by more than one distinct peak and the range of frequencies drops compared to slug flow to between 0 and $5 \mathrm{~Hz}$, with the predominate frequencies also diminishing with higher gas velocities.

Figures 8 (a) and (b) show the peak frequency and the RMS of void fraction fluctuations. Figure 8 (a) shows that the peak frequency varies between $0.75 \mathrm{~Hz}$ to $1.8 \mathrm{~Hz}$ and the value drops with the increase of gas flowrate. This could be explained as with the increase of gas flow rate, the smaller gas bubbles coalesces into larger bubbles leading to the reduction of high frequency components. As the flows approach churn flows, this study observed a range of dominant frequencies due to complex interaction between phases with the most significant frequencies remaining constant at about $0.8-1 \mathrm{~Hz}$. Figure 6 (b) shows that the RMS of void fraction fluctuations drops with the increase of the superficial gas velocity. This 
observation can be explained as the increased chaotic nature of churn flows demonstrated by random void fractions appearing at diverse frequencies compared to the more periodic nature of moderate slug flow patterns where fluctuation energy is concentrated within a narrow band of frequencies. The fluctuation energies in flows close to or in churn flows are distributed over a large frequency ranges and the RMS of void fraction fluctuations drops considerably.

\subsubsection{Effects of liquid velocity on area-averaged void fraction}

Figure 9 shows the predicted void fraction fluctuations and their power spectral density for superficial gas velocities varied between $0.45 \mathrm{~m} / \mathrm{s}$ and $5 \mathrm{~m} / \mathrm{s}$, while keeping the superficial liquid velocity constant at $5 \mathrm{~m} / \mathrm{s}$. According to the flow regime map of Mishima and Ishii [37] these velocities falls within the slug flow regime, with the lowest liquid velocity at the slugannular boundary, while the highest liquid velocity falls near the slugbubbly flow boundary. As shown in Figure 9, the volume fraction contour plot at 5 seconds of flow development has been captured well in the simulation.

Figure 10 shows the predicted void fraction fluctuations and their power spectral density for different superficial gas velocities. Main features of these plots are that as the liquid velocity increases the void fraction fluctuations towards higher frequency and the void fraction values varies between $20 \%$ to $80 \%$. The PSD plots shows that the effects of increasing liquid is to broaden the frequency range upto $0-30 \mathrm{~Hz}$.

Figures 11 (a) and (b) show the dominant frequency and the RMS value of volume fraction fluctuations. The peak frequency increases with the increase of the liquid velocity as the higher liquid content creates greater number of liquid slug while keeping the length and velocity of each liquid slug body constant for a given gas flow rate (as shown in Figure 9). Thus, with the increase of liquid velocity, more slug bodies collide with the bend resulting in the higher frequency at the increased liquid velocity. With further increase of liquid velocity, the two-phase flow regime reaches near 
the bubbly flow and thus, the peak frequency drops significantly. The RMS of void fraction fluctuation shows a slight upward trend with the increase of superficial liquid velocity.

\subsection{Two-phase flow induced force}

The fluctuating force acting on the elbow has been calculated using momentum balance on a control volume at the elbow. Figure 12 shows the control volume at the elbow used for the force calculation. The time dependent forces acting on the elbow can be calculated from the CFD simulation data using the momentum balance equations:

$F_{x}(t)=\dot{m}(t) V(t)+p(t) A$-at the exit plane of the bend

$F_{y}(t)=-\dot{m}(t) V(t)-p(t) A$-at the inlet plane of the bend

$\dot{m}(t)=\left[\alpha(t) \rho_{g}+(1-\alpha(t)) \rho_{l}\right] A V(t)$

where, $\dot{m}(t)$ is instantaneous mass flow rate at inlet or outlet plane of the control volume, $\alpha(t)$ is instantaneous area-averaged gas volume fraction at the inlet or outlet plane of the control volume, $p(t)$ is instantaneous area averaged pressure perpendicular to the flow direction at the inlet or outlet plane of the control volume, $V(t)$ is instantaneous area averaged velocity at the inlet or outlet plane of the control volume.

While applying for the momentum balance calculations using equations (17) and (18), it should be noted that the unsteady $k-\epsilon$ turbulence model used in the present study cannot predict the turbulence pressure fluctuations. In present study, the unsteady $k-\epsilon$ model predicts the fluctuating force stemming predominantly from the intermittent impact of liquid structures on the elbow. However, for the slug and churn flows impacting at the elbow, almost all unsteady behaviour stems from the interface surface dynamics and the impact of liquid and gas structures, Indeed, Liu et (13) shows that the RMS of fluctuating forces are strongly correlated to the RMS of fluctuating momentum fluxes based on the experimental data analyses. Therefore, the application $k-\epsilon$ turbulence model with VOF multiphase 
model is well capable of flow model for predicting the force fluctuations in multiphase slug and churn flows within reasonable accuracy.

\subsubsection{Effects of gas velocity on the force at the bend}

Figures 13(a) and (b) show the comparison of simulated and experimental force fluctuations and their PSDs for the churn flow pattern $\left(V_{s l}=0.61 \mathrm{~m} / \mathrm{s}\right.$ and $\left.V_{s g}=9.04 \mathrm{~m} / \mathrm{s}\right)$. The present CFD prediction shows very good agreement with the experimental results of Liu et al. (13) for time signal as well as PSD. A predominant frequency of approximately $1.9 \mathrm{~Hz}$ and the maximum PSD of approximately $99 \mathrm{~N}^{2} / \mathrm{Hz}$ were observed for both present study and reported experiment (13).

Figures 14 (a) and (b) show the simulated time signals of force fluctuations in $x$ and $y$ directions and their corresponding PSDs. In slug flow regime, the $y$-component of force fluctuations are higher than the $x$-components. However, as the flow regime tends towards churn flow, with the increase of gas velocity, the force fluctuations in $\mathrm{x}$ and $\mathrm{y}$ direction becomes similar. In slug flows, the impact of liquid on the bend cause the higher fluctuations in the $y$-direction similar to water hammer effect. The force fluctuations in slug flows spread over a range of frequency level and the relative importance of higher frequency $(>2 \mathrm{~Hz})$ is also observed in Figures $14(\mathrm{~b})$ (i) - (V). However, in churn flow regime the importance of higher frequencies diminishes as shown in 14(b) (vi) - (vii). This is in contrast to the presented frequency domain results for void fraction fluctuations shown in Figures 7(a) and 7 (b). Force fluctuations spread over smaller ranges compared to the void fraction fluctuations. Liu et al. (13) also reported similar observations.

Figures 15 and 16 present the predominant frequency and the RMS of force fluctuations in the $x$ and $y$ direction, respectively. The predominant frequency of $x$ and $y$ component forces are is higher in slug flows and increases with the superficial gas velocity and drops as gas superficial velocity increases towards churn flow regime before increasing again. Liu et al. (13) observed similar behaviour in their experimental study. The range of RMS values for the $x$ and $y$ force components were $0.89-16.6 \mathrm{~N}$ 
and $2.5-18.5 \mathrm{~N}$ respectively for a mixture velocity of $1.142-9.682 \mathrm{~m} / \mathrm{s}$. Liu et al. (13) obtained values of approximately $2-14 \mathrm{~N}$ and $4-24 \mathrm{~N}$ for similar velocity range. The RMS values obtained by Riverin et al (10) was from $1-12 \mathrm{~N}$ for similar flow conditions and mixture velocities of $2-12$ $\mathrm{m} / \mathrm{s}$. It should be noted that the multiphase flow regimes and the transformation from slug to churn flows depends on many factors including fluid properties, pipe size, shape, developing length and the injection methods and thus direct comparison of force fluctuation frequencies, PSDs and RMS values are rather difficult among different studies. However, the present results replicate the previous studies within a good accuracy level.

\subsubsection{Effects of liquid velocity on forces at the bend}

Figures 17(a) and (b) show the time series of force fluctuations and PSDs of force fluctuations. With the increase of liquid superficial velocity, the fluctuations of both vertical and horizontal components increases and shows very similar patterns. The PSD plots also show that with the increase of the superficial velocity, the range of frequencies reach above $20 \mathrm{~Hz}$ and shows multiple peak frequencies. Figures 18 and 19 show the predominant frequency and the RMS values of fluctuations of forces for different superficial liquid velocities. The predominant frequency increases with the increase of superficial liquid velocity quite rapidly initially and starts to drop as the flow tends to approach bubbly flows. On the other hand, higher liquid content increases the RMS of force fluctuations with the increase of superficial liquid velocity rapidly.

In summary, the increase of gas reduces the range of frequency of force fluctuations, while the increase of liquid broadens the range of frequency of the force fluctuations.

\subsubsection{Origin of Force Fluctuations}

The momentum theory applied in the present study to calculate fluctuating forces indicate that the wall shear stress and pressure forces acting on the wall is equivalent to the momentum flux fed into and out of the control 
volume around the elbow as well as pressure on the face of inlet and outlet of the control volume. Further details on the control volume analysis has been given by Liu at al. (13). Figure 20 and 21 show the relative importance of the fluctuations of the momentum flux and fluid pressure on the resultant force fluctuations. It is shown from these figures that RMS values of the force fluctuations are strongly correlated with that of the momentum flux, while that of pressure fluctuations are weakly correlated. It should be noted that the applied U-RANS modelling in the present study is not capable of predicting pressure fluctuations due to turbulence. The pressure fluctuations observed in the pressure study stems from cyclic flow of fluid and gas bodies in the slug flow and churn flows. In can be concluded that the major force fluctuations are caused by the momentum flux fluctuations. In physical sense that means the force fluctuations originate from the cyclic impact of liquid structures on the bend similar to water hammer effects. In single phase flows, the impact force may not be significant, as the established pressure gradient in the flow is enough for negotiating the bend from vertical to horizontal direction. In slug and churn flows, the established pressure gradient by continuous gas phase is not enough to overcome the inertia of liquid elements. The impact of these liquid elements on the elbow bend structure that causes the force fluctuations as evidenced in the RMS of force fluctuations closely related to force fluctuations. The impact of liquid elements on can also be observed in contour plots of void fraction in Figures 4 and 9. These figures show that after the liquid impacts on the bend, the liquid bodies lose their structures and flows as thin film along the horizontal section of the pipe.

\subsubsection{Non-dimensional RMS of excitation force}

Riverin et al. (10) developed a correlation to predict the RMS of force fluctuations using their experimental data of U-bend and T-junction and other available reported data. Their correlation has been developed for the gas volume fraction in the range of $50-75 \%$ and are given by:

$\overline{F_{r m s}}=\frac{F_{r m s}}{\rho V_{t}^{2}\left(\frac{\pi D^{2}}{4}\right)}=10 W e^{-0.4}$ 
where, $\overline{F_{r m s}}$ is the normalised RMS value of the fluctuating force, We is the Weber number defined as

$W e=\frac{\rho_{m} V_{t}^{2} D}{\sigma}$

Figure 22 shows the comparison of the present simulation data of normalised RMS force fluctuation against the Riverin et al (10) correlation. In the present study, the ranges of gas void fraction varies between 40$90 \%$. Though the data from present study shows some spread, however, most of the present prediction data falls within $\pm 50 \%$ of the correlations, which is a better match compared to the experimental study of Liu et al. (13), upon which the present study is based on. Riverin et al. (10) correlation was developed for the gas void fraction in the range of $50-75 \%$ and the present study data within this range shows an excellent match with the correlation.

\section{Conclusion}

CFD simulations of flow induced vibration at pipe bend due to multiphase slug and churn flows have been carried out using the volume of fluid (VOF) model for two-phase flows and and the $k-\epsilon$ model for turbulence representation. . The present study is focused on characterising the slug and churn flow induced forces on a $90^{\circ}$ pipe bend without the effect of the pipe structure response. The simulation results were compared with reported experiment data of time series of volume fraction and excitation forces and the results show a very good conformation of CFD results with experimental data.

The simulation results show that the peak gas volume fraction frequency varies between $0.5-9 \mathrm{~Hz}$ with the values decreasing with the increase of superficial gas velocity, and increasing with the increase of superficial liquid velocity in the slug flow regimes. The gas volume fraction fluctuation 
frequencies drops as the flow approach the transition boundary from slug flows to annular or bubbly flow. The frequency of gas volume fraction fluctuations is broadband and spreads over $30 \mathrm{~Hz}$.

Furthermore, the force time variations have been calculated using momentum balance at the pipe elbow. The simulated time domain signal of forces for churn flow and its frequency domain PSD matched well with the experiment data. The peak frequency of the fluctuations of force varies between $0.5-1.7 \mathrm{~Hz}$ and drops with the increasing superficial gas velocity. The frequency of fluctuations of force spreads below $10 \mathrm{~Hz}$ and Contrary to volume fraction fluctuations, , the RMS of force fluctuations increases with the superficial gas velocity. With the increase of superficial liquid velocity, the peak frequency of fluctuations of force varies between $1-7 \mathrm{~Hz}$ and increases initially and the drops at higher superficial liquid velocity as the flow approaches bubbly flow. The PSD of fluctuation of force spreads over $20 \mathrm{~Hz}$ with the increase of superficial liquid velocity. The RMS of force fluctuations increases with the increase of superficial liquid velocity. It can be concluded that the increase of gas fraction narrows the range of frequency ranges, while increasing the liquid expands the frequency ranges of force fluctuations. Finally, the present study shows very good match of RMS of resultant force fluctuations with Riverin et al.(10) correlation.

\section{Funding}

This work was supported by the Commonwealth Scholarship Commission in the UK for Nkemjika Mirian Chinenye-Kanu's PhD study.

\section{Nomenclature}

A Pipe cross sectional area, $\mathrm{m}^{2}$

$\mathrm{F} \quad$ External body forces, $\mathrm{N}$

$F^{\prime} \quad$ Force fluctuation, $N$

$\mathrm{p}$ Pressure, $\mathrm{Pa}$

$\mathrm{t}$ Time, $\mathrm{s}$

$\vec{v}_{m} \quad$ Mixture velocity, $\left.\mathrm{m} / \mathrm{s}\right\}$ 
$\bar{u} \quad$ Velocity component in $\mathrm{i}, \mathrm{j}=1,2$ or 3 directions, $\mathrm{m} / \mathrm{s}$

$\mathrm{V}_{\mathrm{sg}} \quad$ Gas superficial velocity, $\mathrm{m} / \mathrm{s}$

$\mathrm{V}_{\mathrm{sl}} \quad$ Liquid superficial velocity, $\mathrm{m} / \mathrm{s}$

$C_{\mu}, C_{1 \epsilon}, C_{2 \epsilon}$, Coefficients in approximated turbulent transport equations

$\mathrm{A}_{\mathrm{g}} \quad$ Surface area of gas inlet, $\mathrm{m}^{2}$

$A_{l} \quad$ Surface area of liquid inlet, $\mathrm{m}^{2}$

$\mathrm{V}(\mathrm{t})$ Instantaneous velocity, $\mathrm{m} / \mathrm{s}$

\section{Greek letters}

$\rho \quad$ Density, $\mathrm{kg} / \mathrm{m}^{3}$

$\mu \quad$ Dynamic viscosity, $\mathrm{kg} / \mathrm{ms}$

$\tilde{\alpha}_{g}^{A} \quad$ Area averaged void fraction

$\rho_{g} \quad$ Gas density, $\mathrm{kg} / \mathrm{m}^{3}$

$\rho_{l} \quad$ Water density, $\mathrm{kg} / \mathrm{m}^{3}$

\section{References}

(1) Parameshwaran, R., Dhulipalla, S.J., Yendluri, D.R. Fluid-structure interactions and flow induced vibrations: a review. Procedia Engineering. 2016; 144:1286-1293.

(2) Energy Institute. Guidelines for the avoidance of vibration induced fatigue failure in process pipework. UK: 2008.

(3) Hill, J. Managing the Integrity Threat of Subsea Pipework Fatigue Failure. [homepage on the Internet]. UK: Xodus Group; 2012 cited 2015 11/27]. Available from:

http://www.subseauk.com/documents/xodus $\% 20$ group $\% 20$ \%20subsea\%20europe\%20paris\%202011.pdf.

(4) Ter Hofstede, E., Kottapalli, S., Shams, A. Numerical prediction of flow induced vibrations in nuclear reactor applications. Nuclear Engineering and Design. 2017; 319:81-90.

(5) Pettigrew, M., Taylor, C. Two-phase flow-induced vibration: An overview (survey paper). Journal of Pressure Vessel Technology. 1994; $116(3): 233-253$. 
(6) Yih, T.S. and Griffith, P., Unsteady momentum fluxes in two-phase flow and the vibration of nuclear reactor components. Cambridge, Mass.: MIT Dept. of Mechanical Engineering, 1968.

(7) Bossio V ,V.Boris M., Blanco A ,A.Armando J., Casanova M ,M.Euro L. Numerical modelling of the dynamical interaction between slug flow and vortex induced vibration in horizontal submarine pipelines. Journal of Offshore Mechanics and Arctic Engineering. 2014; 136(4):1-5.

(8) Cooper, P., Burnett, C., Nash, I. Fatigue design of flowline systems with slug flow. Fatigue design of flowline systems with slug flow. 28th International Conference on Ocean, Offshore and Arctic Engineering, OMAE2009, May 31, 2009 - June 5; 2009; Proceedings of the International Conference on Offshore Mechanics and Arctic Engineering $O M A E$, Honolulu, HI, United states: American Society of Mechanical Engineers; 2009. p. 207-212.

(9) Tay, B.L. and Thorpe, R.B. Effects of liquid physical properties on the forces acting on a pipe bend in gas-liquid slug flow. Chemical Engineering Research and Design, 2004; 82(3):344-356.

(10) Riverin, J. De Langre, E., Pettigrew, M. Fluctuating forces caused by internal two-phase flow on bends and tees. Journal of Sound and Vibration. 2006; 298(4-5):1088-1098.

(11) Cargnelutti, M.F., Belfroid, S.PC., Schiferli, W., Van Osch, M., Multiphase fluid structure interaction in bends and T-joints. ASME 2010 Pressure Vessels and Piping Division/K-PVP Conference, PVP2010, July 18, 2010 - July 22. 2010. Bellevue, WA, United states: American Society of Mechanical Engineers. 2010:75-82.

(12) Riverin, J.L., Pettigrew, M.J. Vibration excitation forces due to twophase flow in piping elements. Journal of Pressure Vessel Technology, Transactions of the ASME, 2007; 129(1):7-13

(13) Liu, Y., Miwa, S., Hibiki, T., Ishii, M., Morita, H., Kondoh, Y., Tanimoto, K. Experimental study of internal two-phase flow induced 
fluctuating force on a 90 elbow. Chemical Engineering Science. 2012; 76:173-187.

(14) Miwa, S., Mori, M., Hibiki, T. Two-phase flow induced vibration in piping systems. Progress in Nuclear Energy. 2015; 78:270-284.

(15) Lu, Y., Liang, C., Manzano-Ruiz, J., Janardhanan, K., Perng, Y. FSI analysis of flow-induced vibration in subsea jumper subject to downstream slug and ocean current. ASME 2014 33rd International Conference on Ocean, Offshore and Arctic Engineering, OMAE 2014, June 8, 2014 - June 13; 2014; Proceedings of the International Conference on Offshore Mechanics and Arctic Engineering - OMAE; San Francisco, CA, United states.

(16) Pontaza, J.P., Menon, R.G., Okeremi, A., Spritzer, J., Widjaja, S. Flow-induced vibrations of high gas rate well jumpers: Tees vs. Bends. ASME 2013 32nd International Conference on Ocean, Offshore and Arctic Engineering, OMAE 2013, June 9, 2013 - June 14; 2013; Proceedings of the International Conference on Offshore Mechanics and Arctic Engineering - OMAE.

(17) Pontaza, J.P., Abuali, B., Smith, F.J., Brown, G.W. Flow-Induced Vibrations of Subsea Piping: A Screening Approach Based on Numerical Simulation. SPE Offshore Europe Oil and Gas Conference and Exhibition: Society of Petroleum Engineers; 2013.

(18) Miwa, S., Hibiki, T., Mori, M. Analysis of Flow-Induced Vibration Due to Stratified Wavy Two-Phase Flow. Journal of Fluids Engineering. 2016; 138(9):091302.

(19) Abdulkadir, M., Hernandez-Perez, V., Lo, S., Lowndes, I., Azzopardi, B.J. Comparison of experimental and Computational Fluid Dynamics (CFD) studies of slug flow in a vertical riser. Experimental Thermal and Fluid Science. 2015; 68:468-483. 
(20) Gayet, C., N'Diaye, M., Liné, A. Behaviour of Slug Flow and Pressure Force Induced in a Spool: Numerical Simulation of a Taylor Bubble Flowing in a Liquid Flow Through a Spool. 16th International Conference on Multiphase Production Technology: BHR Group; 2013.

(21) Emmerson, P., Lewis, M., Barton, N. Improving boundary conditions for multiphase CFD predictions of slug flow induced forces. 17th International Conference on Multiphase Production Technology: BHR Group; 2015.

(22) Araujo, J.D.P., Miranda, J.M., Campos, J.B.L.M. CFD Study of the Hydrodynamics of Slug Flow Systems: Interaction between Consecutive Taylor Bubbles. International Journal of Chemical Reactor Engineering. 2015; 13(4):541-549.

(23) Ratkovich, N., Majumder, S., Bentzen, T.R. Empirical correlations and CFD simulations of vertical two-phase gas-liquid (Newtonian and nonNewtonian) slug flow compared against experimental data of void fraction. Chemical Engineering Research and Design. 2013; 91(6):988-998.

(24) Da Riva, E., Del Col, D. Numerical simulation of churn flow in a vertical pipe. Chemical Engineering Science. 2009; 64(17):3753-3765.

(25) Parvareh, A., Rahimi, M., Alizadehdakhel, A., Alsairafi, A. CFD and ERT investigations on two-phase flow regimes in vertical and horizontal tubes. International Communications in Heat and Mass Transfer. 2010; 37(3):304-311.

(26) Parsi, M., Vieira, R., Agrawal, M., Srinivasan, V., McLaury, B., Shirazi, S., Schleicher, E., Hampel, U. Computational Fluid Dynamics (CFD) Simulation of Multiphase Flow and Validating Using Wire Mesh Sensor. 17th International Conference on Multiphase Production Technology: 10-12 June Cannes, France, BHR Group; 2015.

(27) Zhu, H., Wang, J., Ba, B., Wu, Z., Wang, W. Numerical investigation of flow erosion and flow induced displacement of gas well relief line. Journal of Loss Prevention in the Process Industries. 2015; 37:19-32. 
(28) Zhu, H., Tang, Y., Wang, J., Tang, L. Flow erosion and flow induced vibration of gas well relief line with periodic fluctuation of boosting output. Journal of Loss Prevention in the Process Industries. 2017; 46:69-83.

(29) Sadek, O., Mohany, A., Hassan, M. Numerical investigation of the cross flow fluidelastic forces of two-phase flow in tube bundle. Journal of Fluids and Structures. 2018; 79: 171-186.

(30) Benguigui, W. Numerical simulation of two-phase flow induced vibration. Mechanics of the fluids [physics.class-ph]. Université Paris-Saclay, 2018. English. NNT: 2018SACLY014. tel-01923252.

(31) Montoya-Hernandez, D.J., Vazquez-Hernandez, A.O., Cuamatzi, R., Hernandez, M.A. Natural frequency analysis of a marine riser considering multiphase internal flow behaviour. Ocean Engineering, 2014; 92:103113.

(32) Youngs, D.L. Time-dependent multi-material flow with large fluid distortion, Numerical Methods for Fluid Dynamics. Atomic Weapons Research Establishment, Aldermaston. 1982.

(33) Ishii, M., Hibiki, T. Thermo-fluid dynamics of two-phase flow, Springer, New York, 2010.

(34) Launder, B.E., Spalding, D.B. The numerical computation of turbulent flows, Computer methods in applied mechanics and engineering. 1974; 3:269-289.

(35) Youngs, D.L. Time-dependent multi-material flow with large fluid distortion, Numerical Methods for Fluid Dynamics. Atomic Weapons Research Establishment, Aldermaston. 1982.

(36) Parsi, M., Agrawal, M., Srinivasan, V., Vieira, R. E., Torres, C. F., McLaury, B. S., Shirazi, S. A., Schleicher, E. and Hampel, U. Assessment 
of a hybrid CFD model for simulation of complex vertical upward gas-liquid churn flow. Chemical Engineering Research and Design. 2016; 105: 7184.

(37) Mishima, K. and Ishii, M. Flow regime transition criteria for upward two-phase in vertical tubes. Int. J. Heat Mass Transfer. 1984; 27: 723737. 


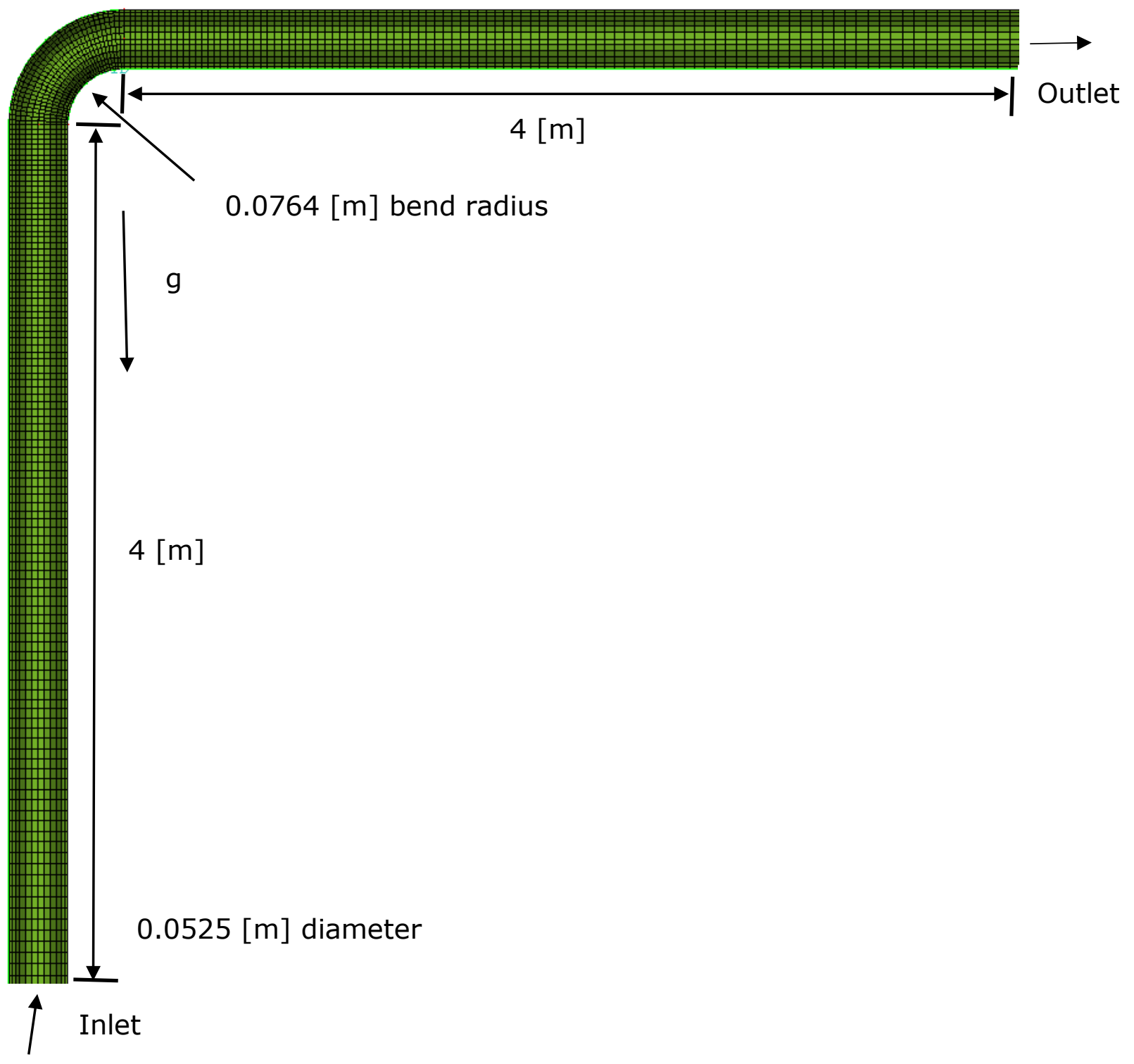

Figure 1: (a) Pipe Geometry 


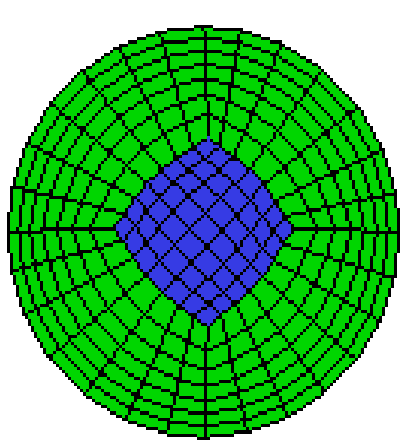

Mesh $1(154840)$

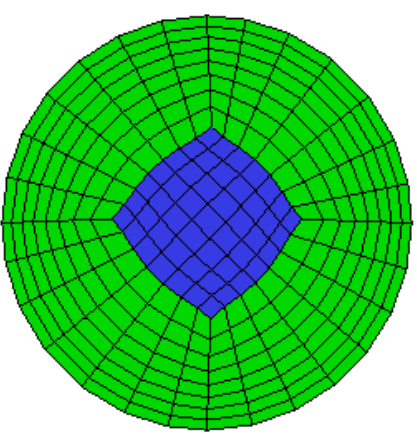

Mesh 2 (227136)

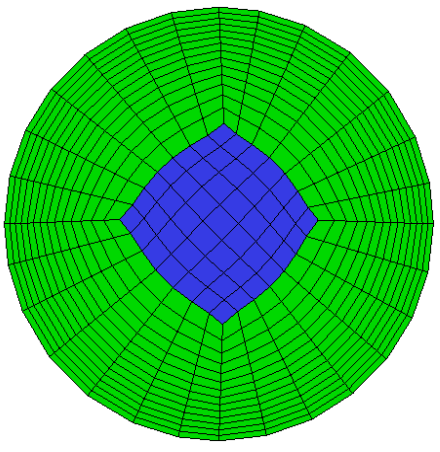

Mesh 3 (366912)

Figure 1: (b) Meshes on the inlet and outlet faces

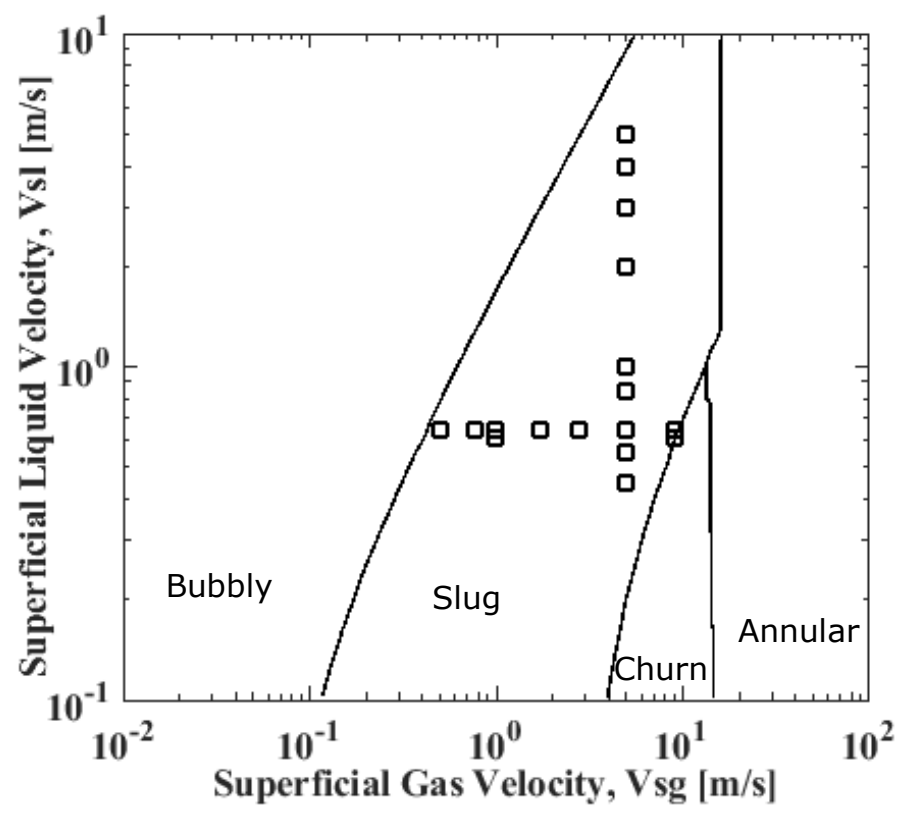

Figure 2: Simulation conditions plotted onto the Mishima and Ishii's [37] flow regime map. 


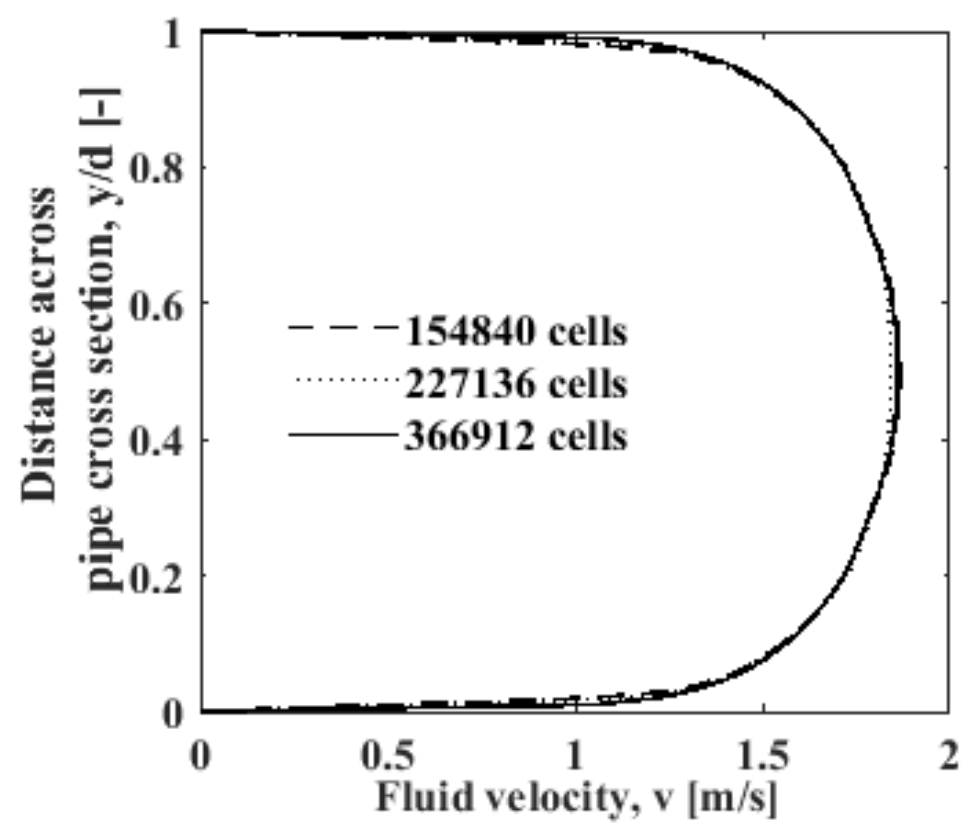

(a)

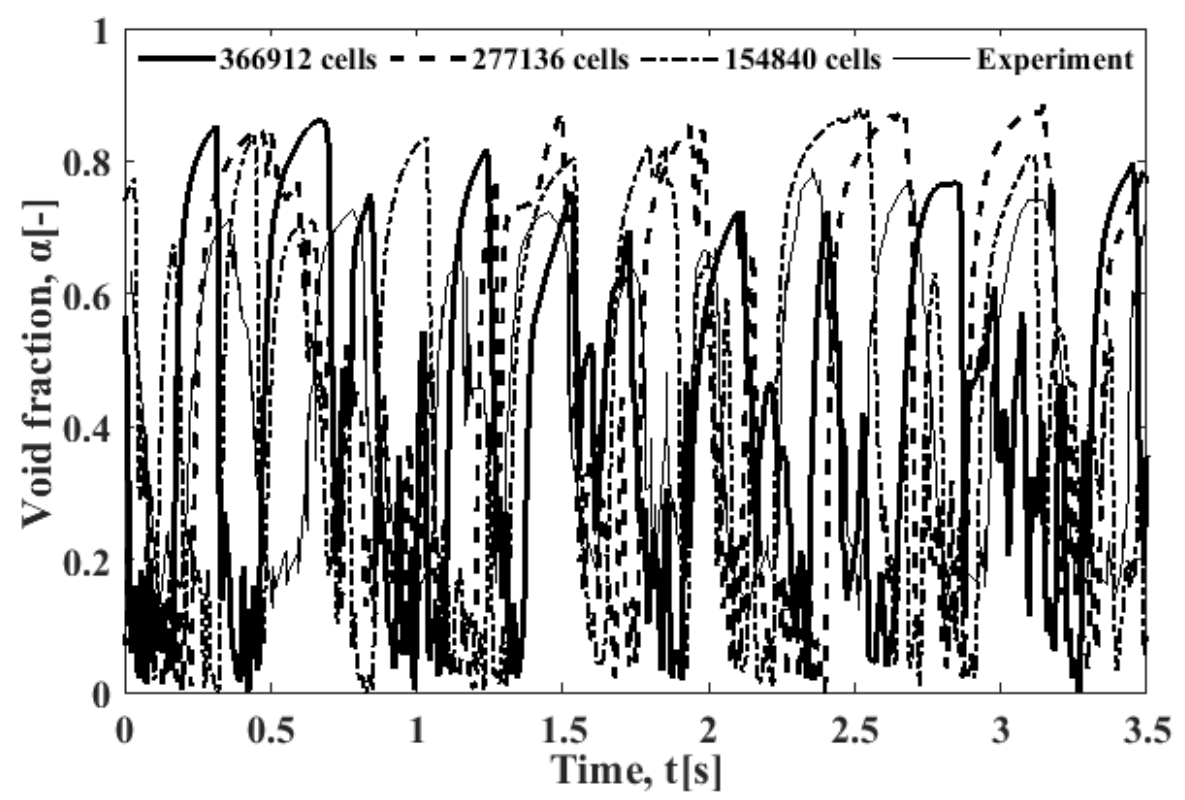

(b) 


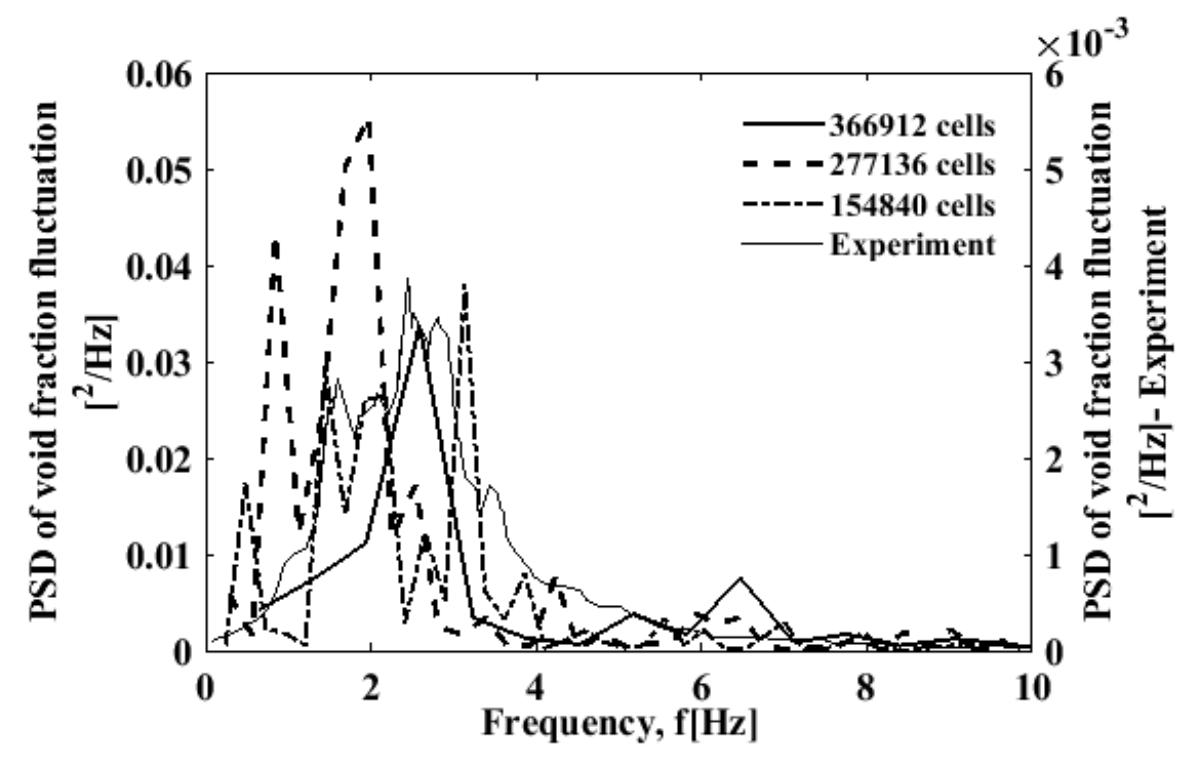

(c)

Figure 3 - Mesh independency test: (a) predicted velocity profiles for the three mesh sizes (b) comparison of time series of void fraction with time (c) comparison of PSD of void fraction fluctuations 


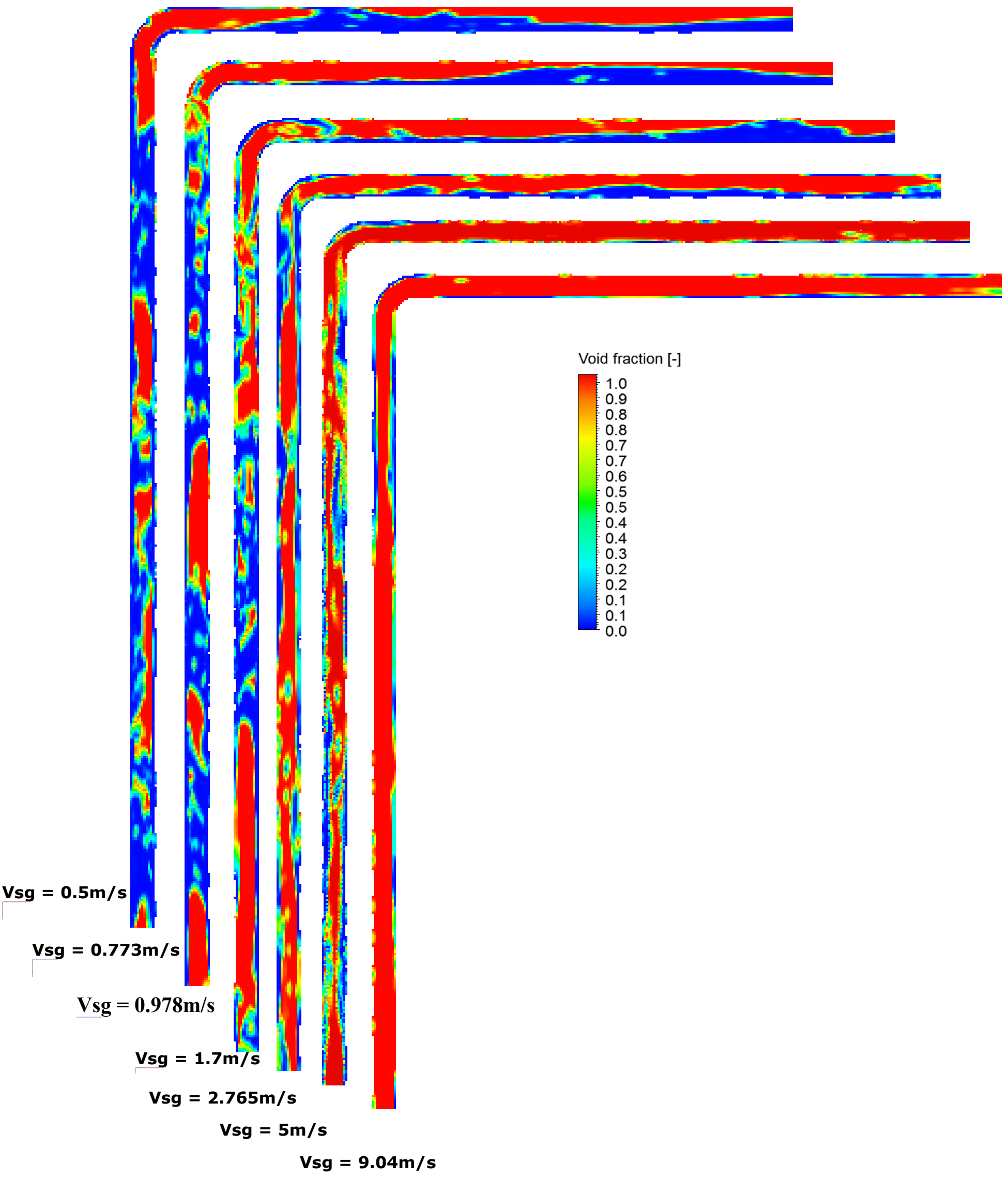

Figure 4: Contour Plot of gas void fraction distribution for different superficial gas velocities for a fixed superficial liquid velocity of $5 \mathrm{~m} / \mathrm{s}$ 
(a)

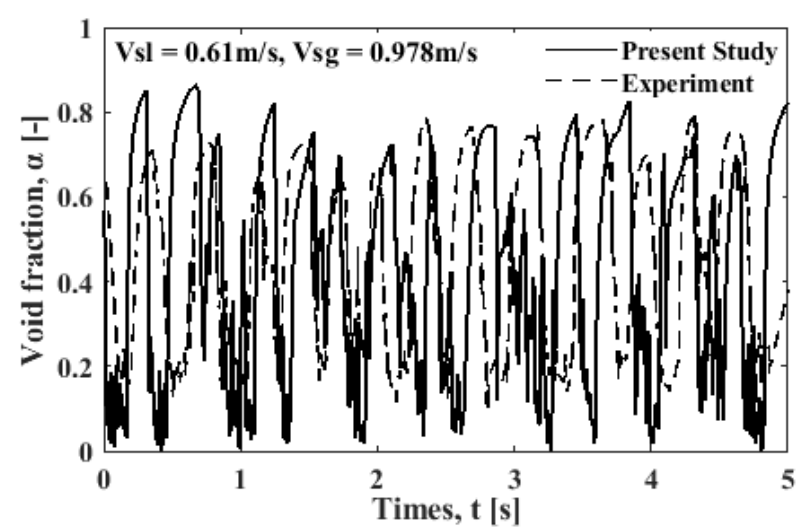

(b)

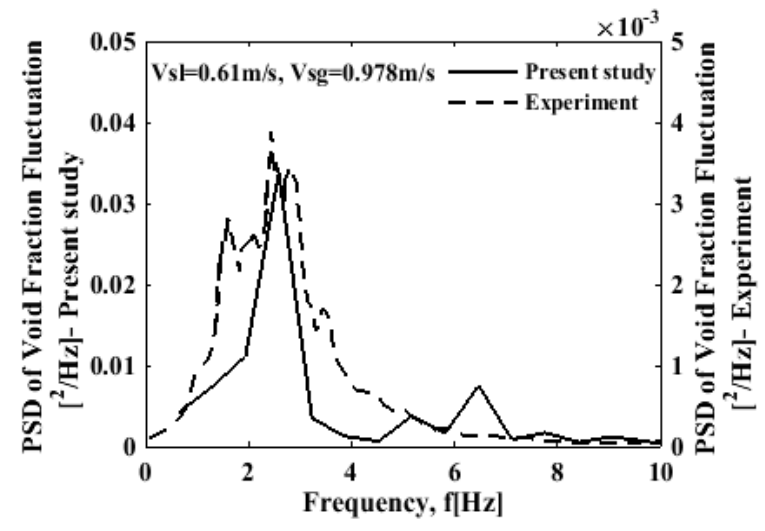

Figure 5: Comparison of void fraction variation with time of present study and experiment (13) result of a typical slug flow (a) Void fraction fluctuation and (b) PSD. 
(a)

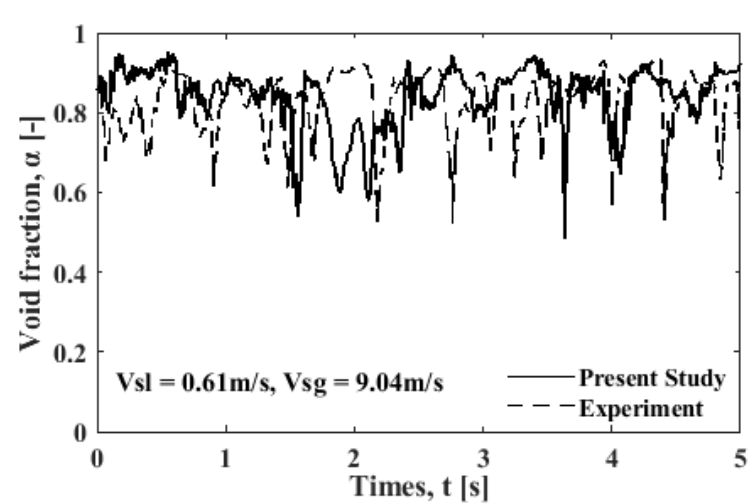

(b)

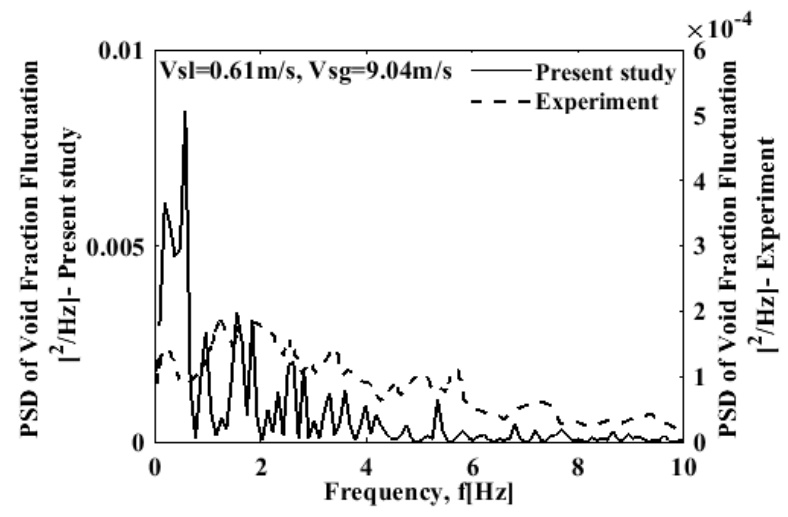

Figure 6: Comparison of void fraction variation with time of present study and experiment (13) result of a typical churn flow (a) Void fraction fluctuation and (b) PSD. 
(i)

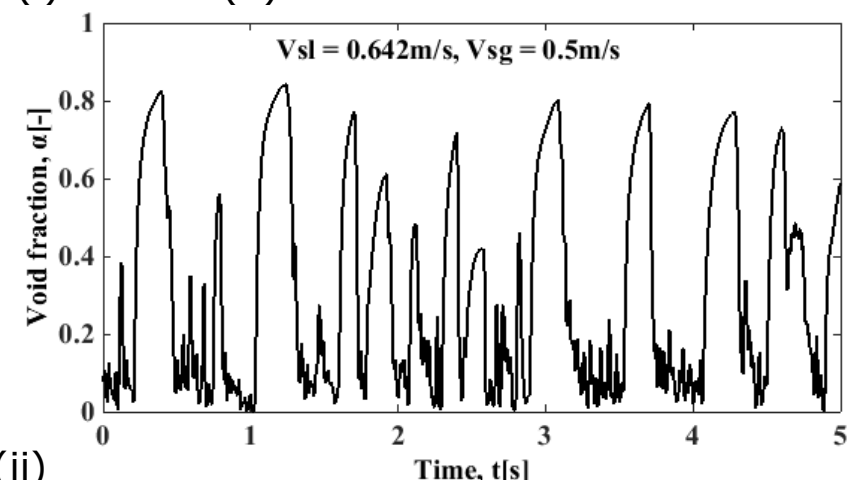

(ii)
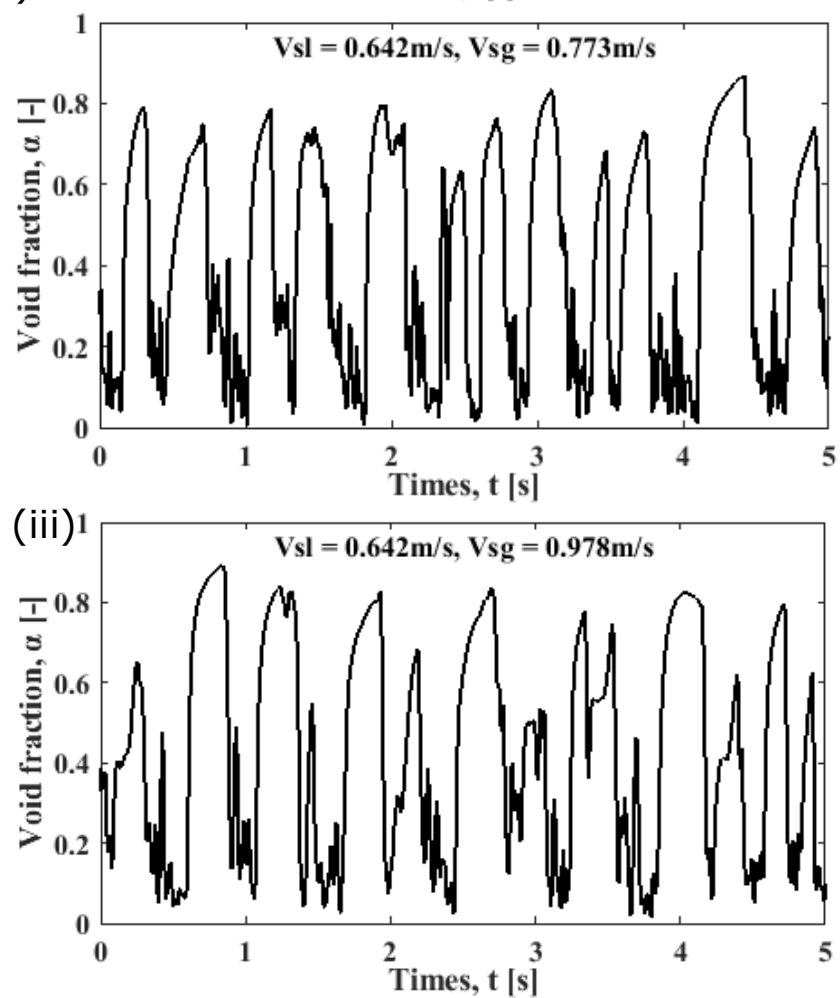

(iv)

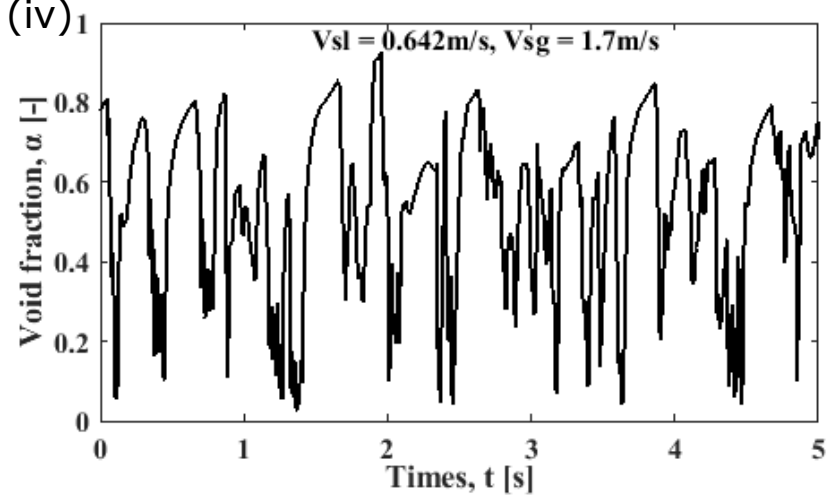

(b)
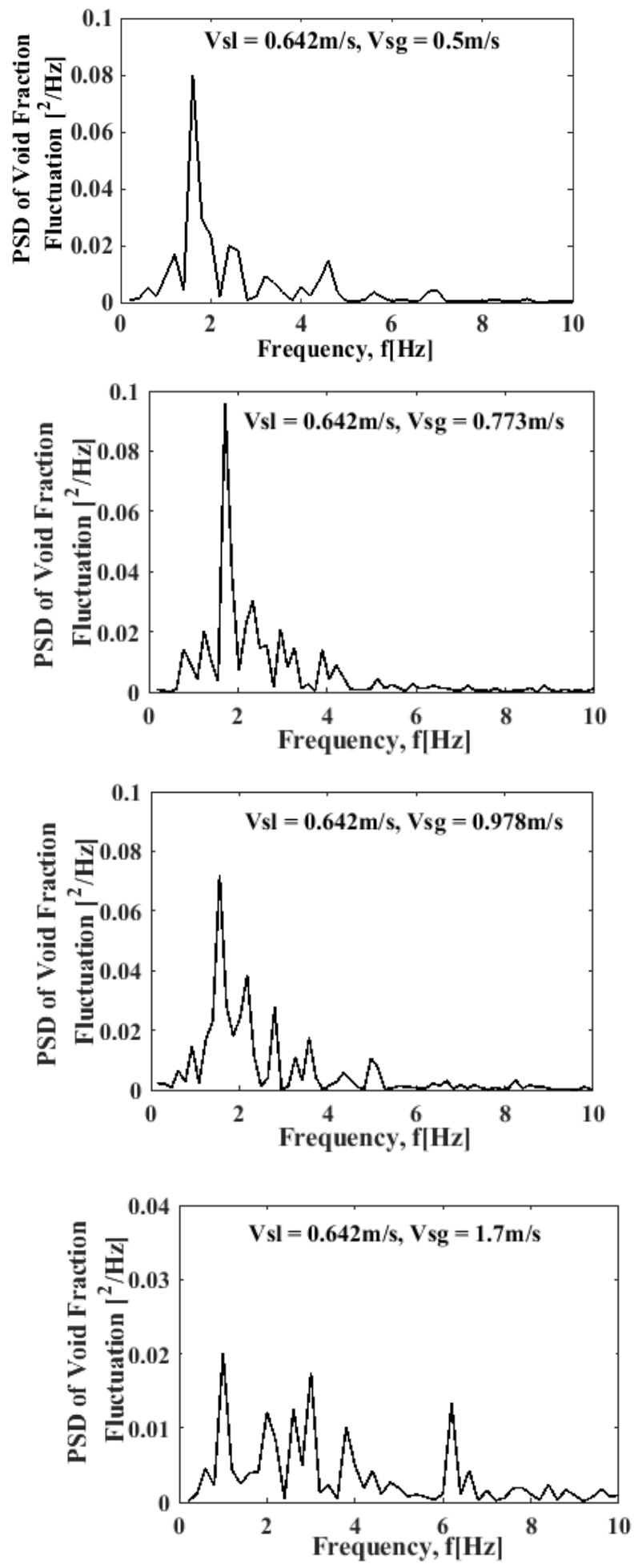
( $v)$
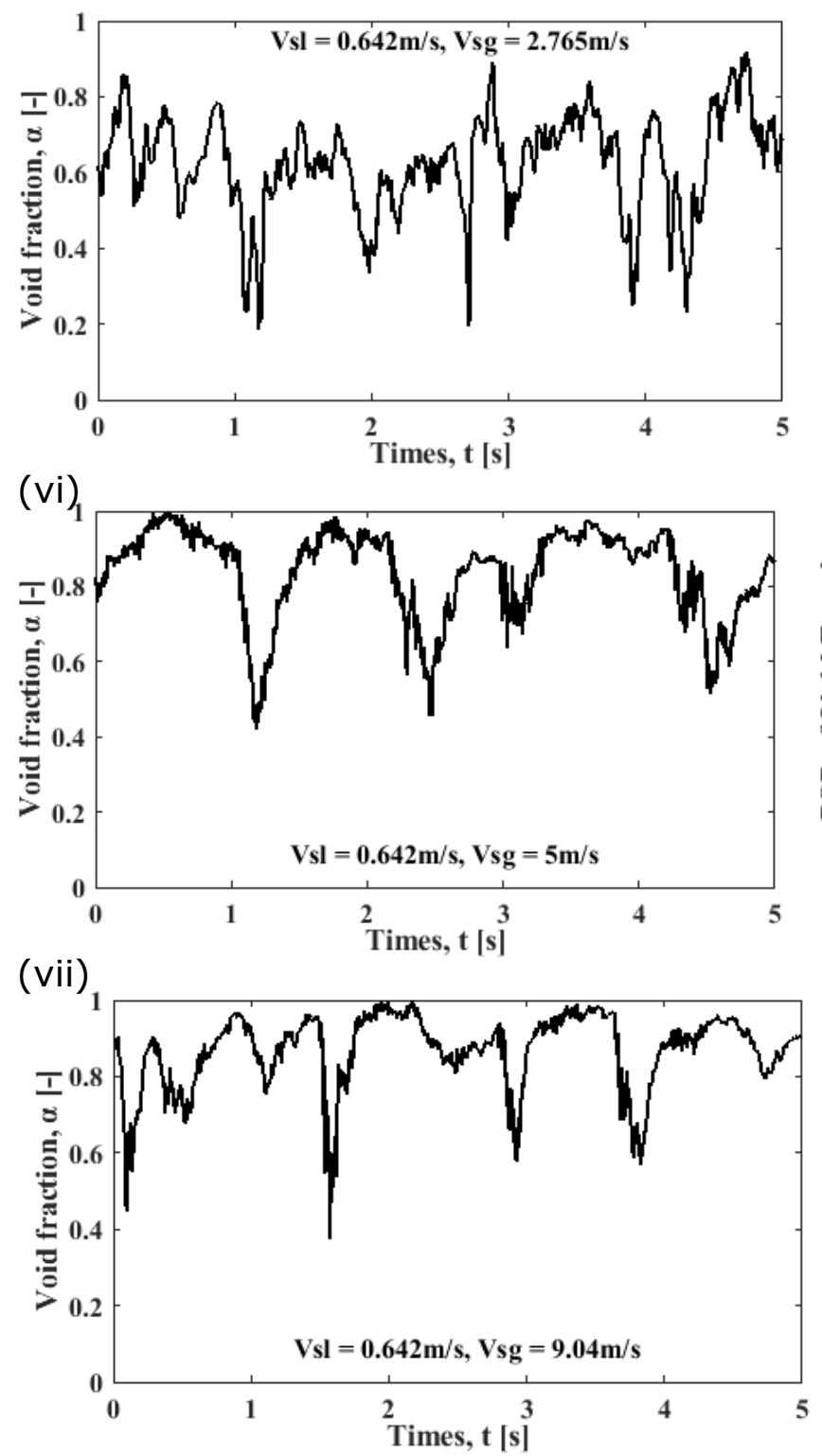

(b)
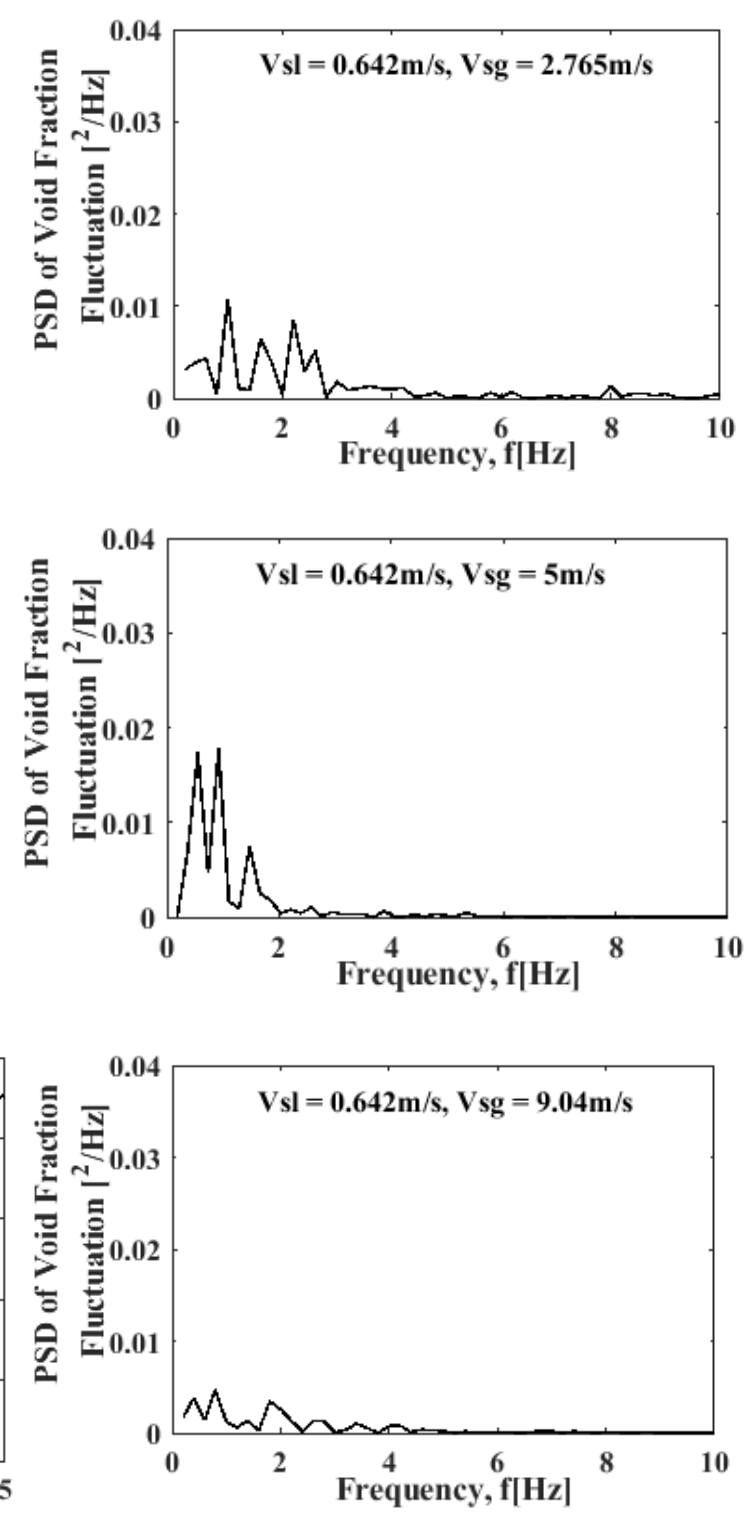

Figure 7: The effect of superficial gas velocity for a fixed superficial liquid velocity of $5 \mathrm{~m} / \mathrm{s}$ (a) Void fraction fluctuation and (b) PSD. 
(a)

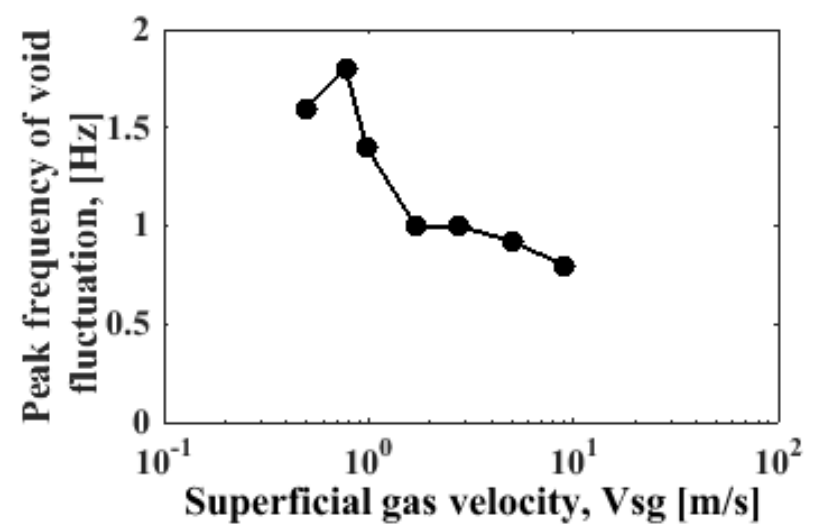

(b)

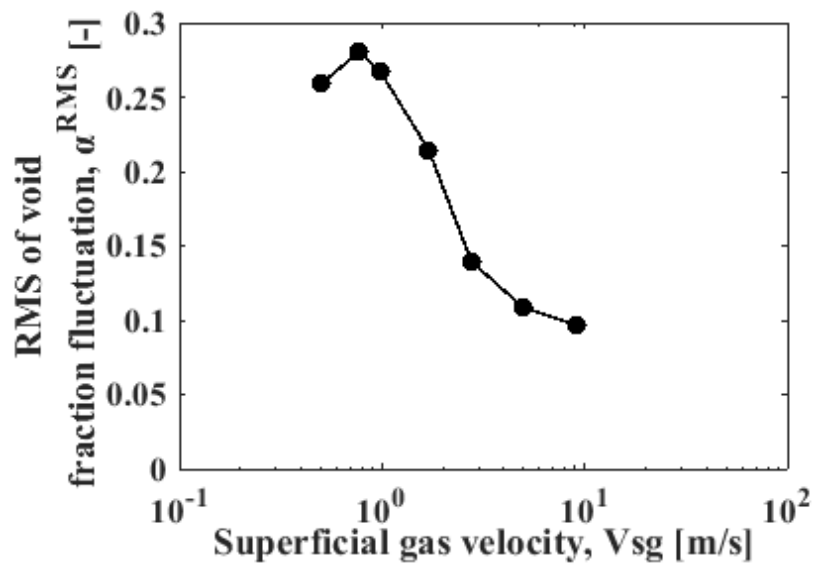

Figure 8: (a) Peak frequency and (b) RMS of void fraction fluctuation for different superficial gas velocities while keeping the superficial liquid velocity fixed at $0.642 \mathrm{~m} / \mathrm{s}$. 


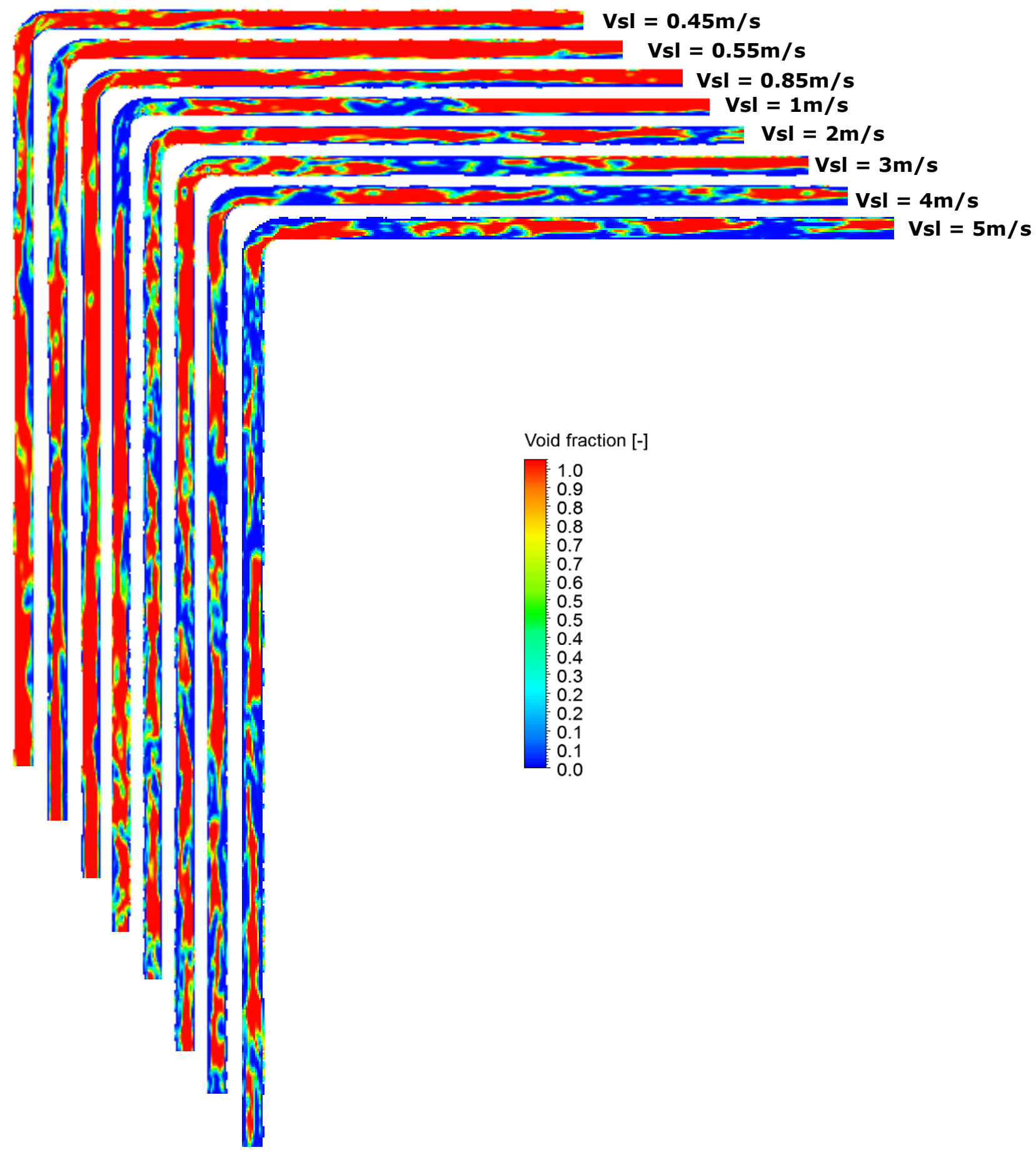

Figure 9: Contour Plot of gas void fraction distribution for different liquid superficial velocity for a fixed superficial gas velocity of $5 \mathrm{~m} / \mathrm{s}$. 
(i)

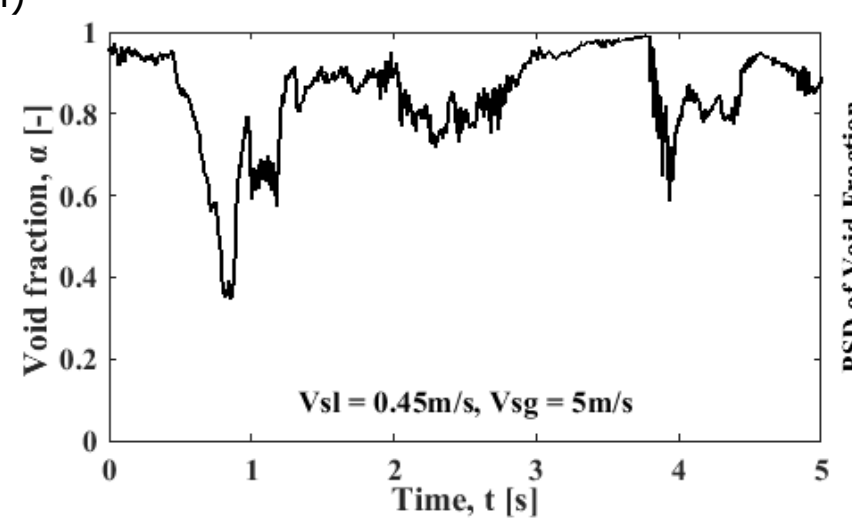

(ii)

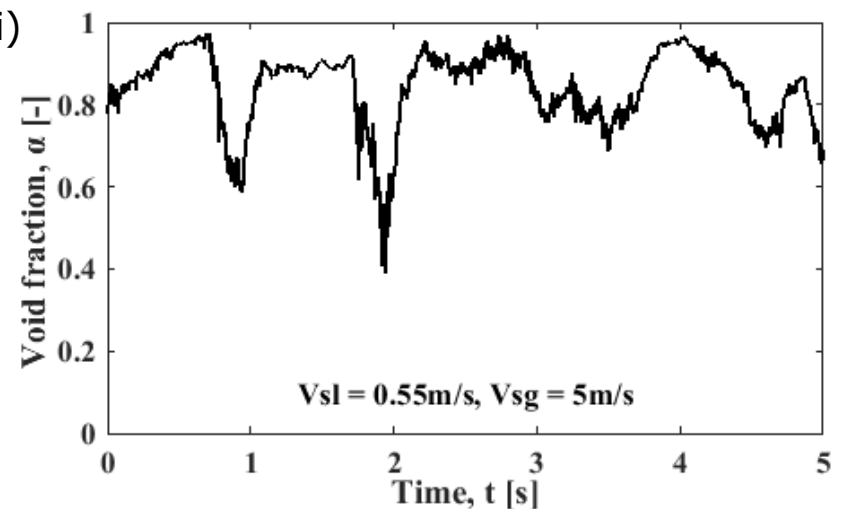

(iii)

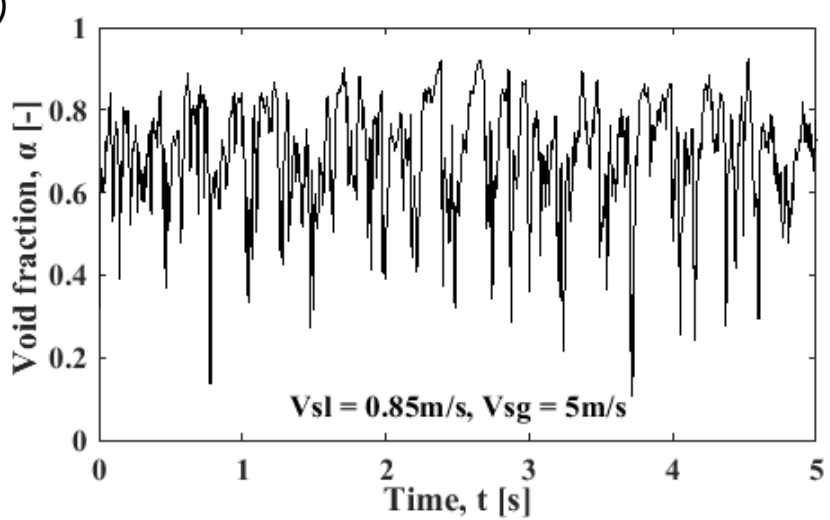

(iv)

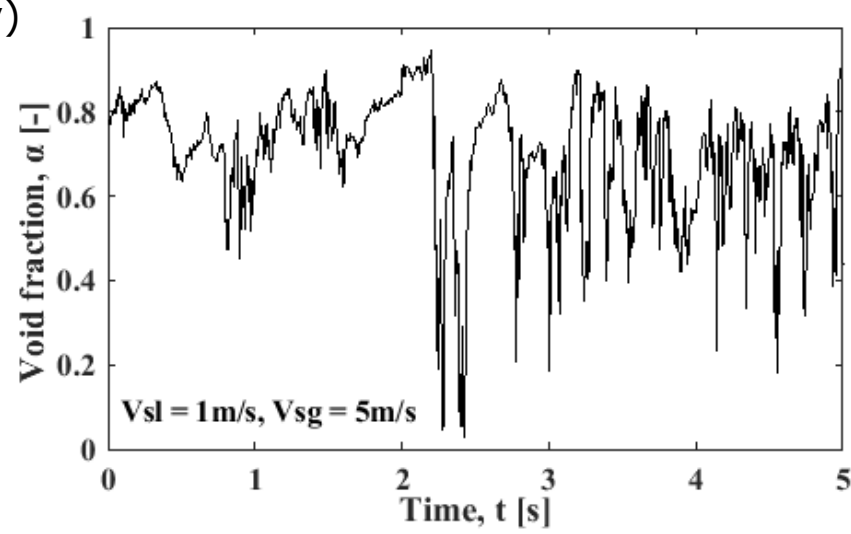

(b)
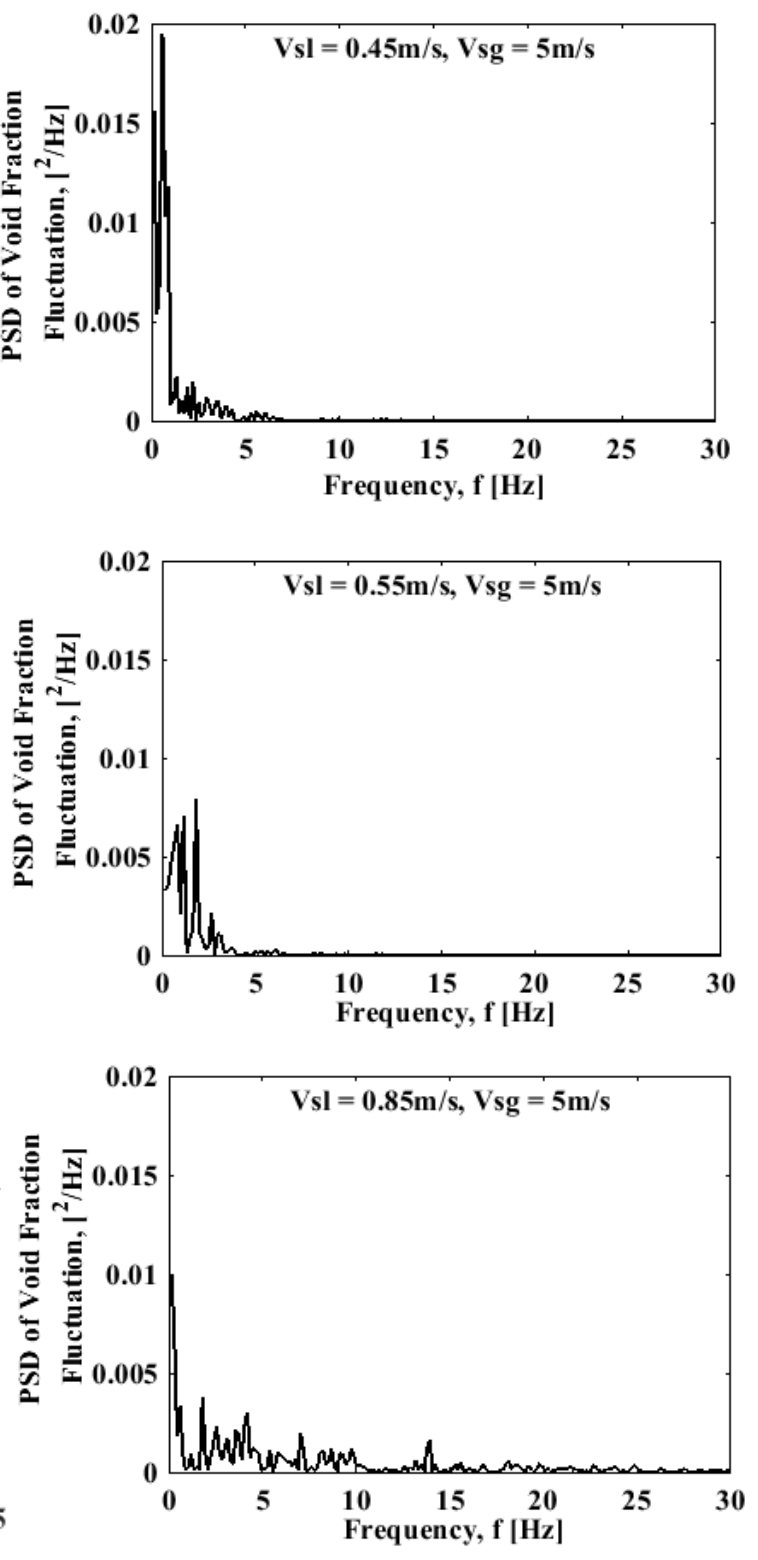
( $v)$

(a)

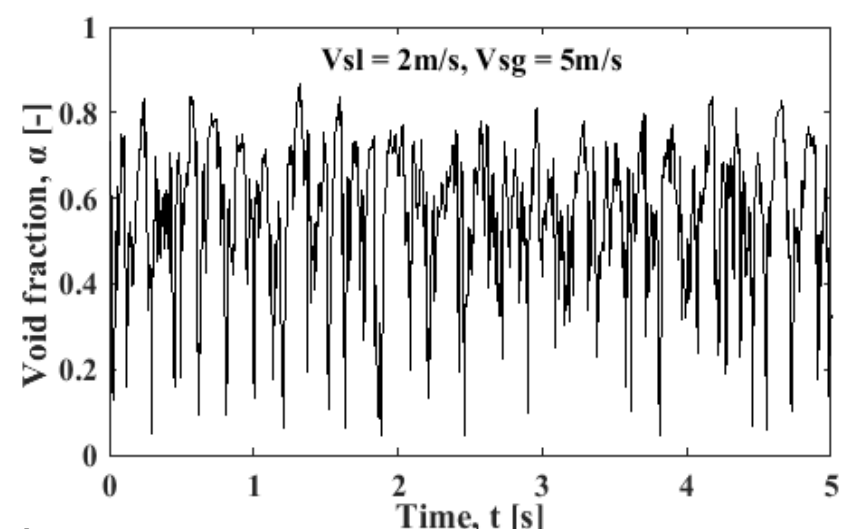

(vi)

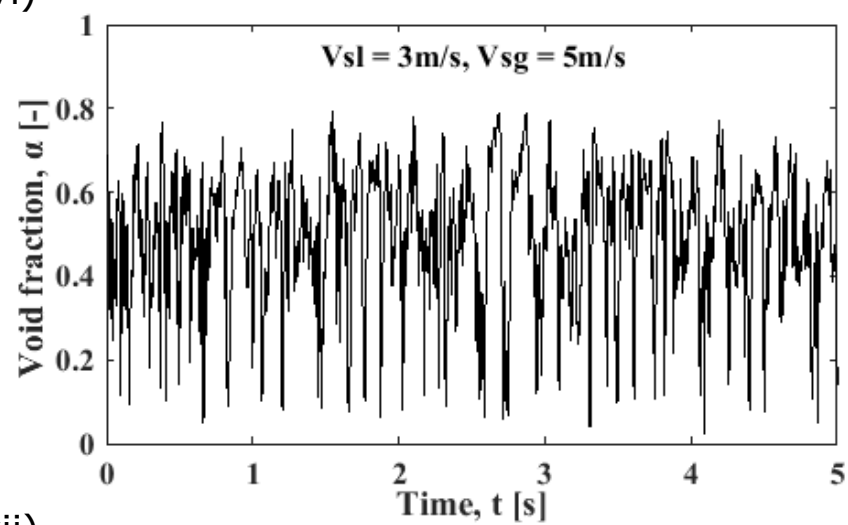

(vii)

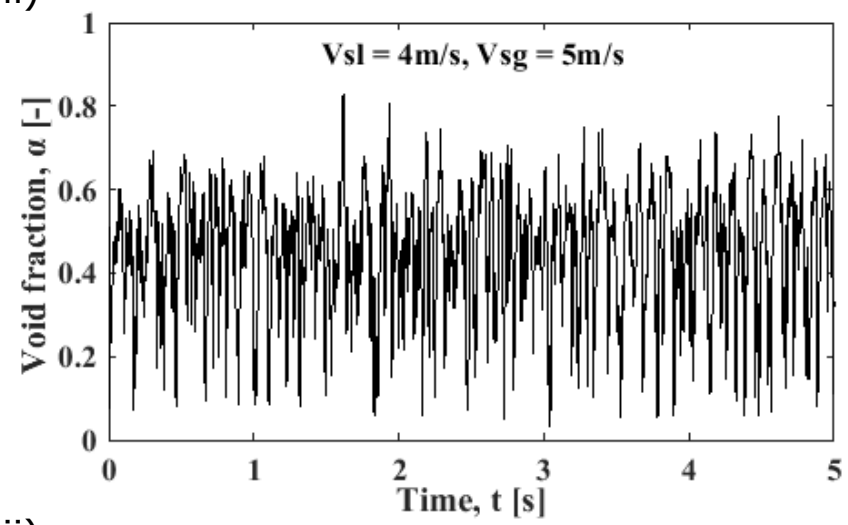

(viii)

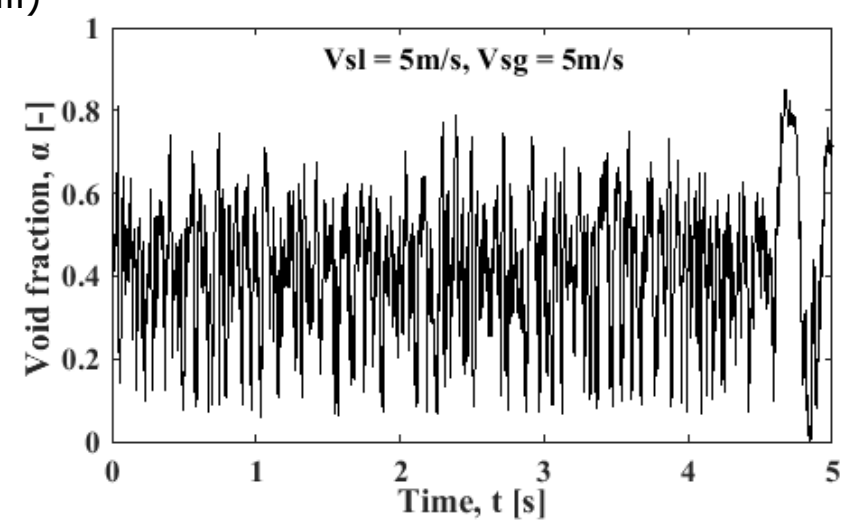

(b)
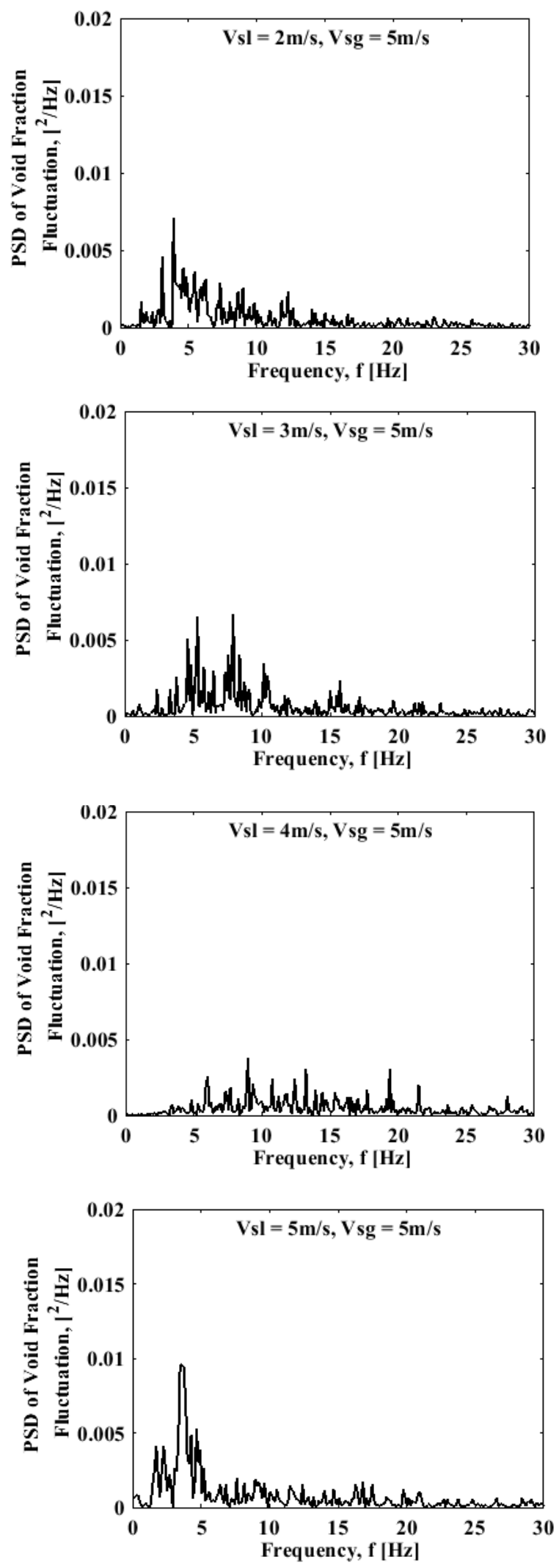

Figure 10: The effect of superficial liquid velocity for a fixed superficial gas velocity of $5 \mathrm{~m} / \mathrm{s}$ (a) Void fraction fluctuation and (b) PSD. 
(a)

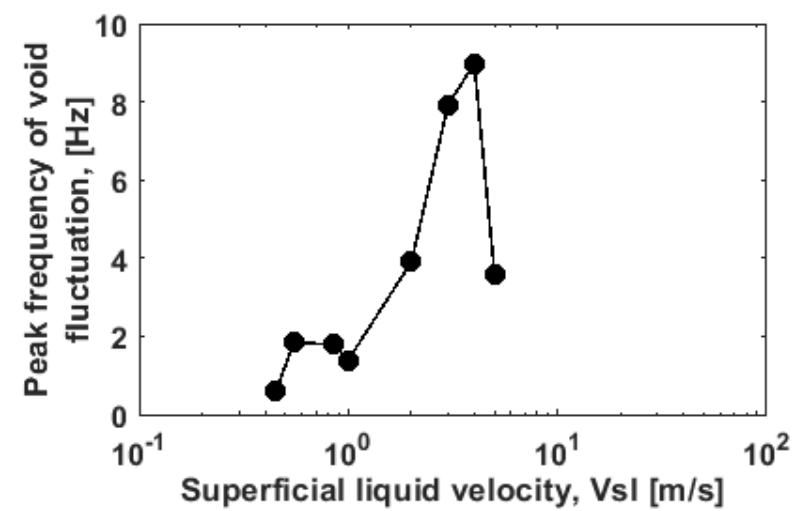

(b)

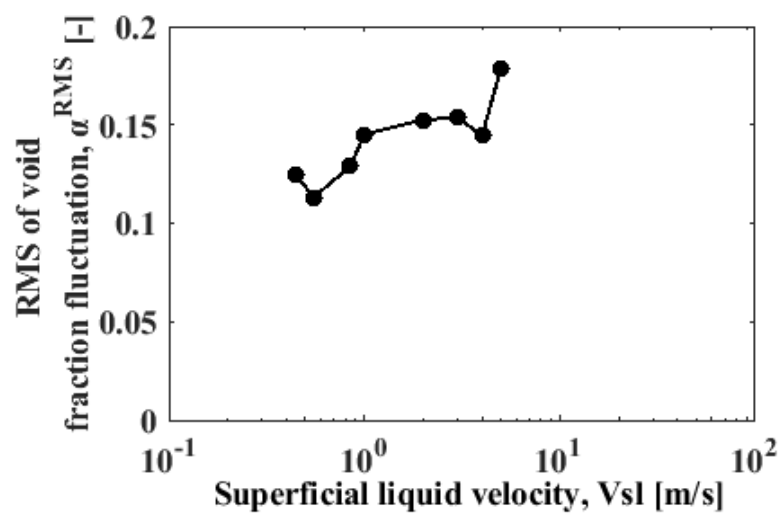

Figure 11: (a) Peak frequency and (b) RMS of void fraction fluctuation for different superficial liquid velocities while keeping the superficial gas velocity fixed at $5 \mathrm{~m} / \mathrm{s}$. 


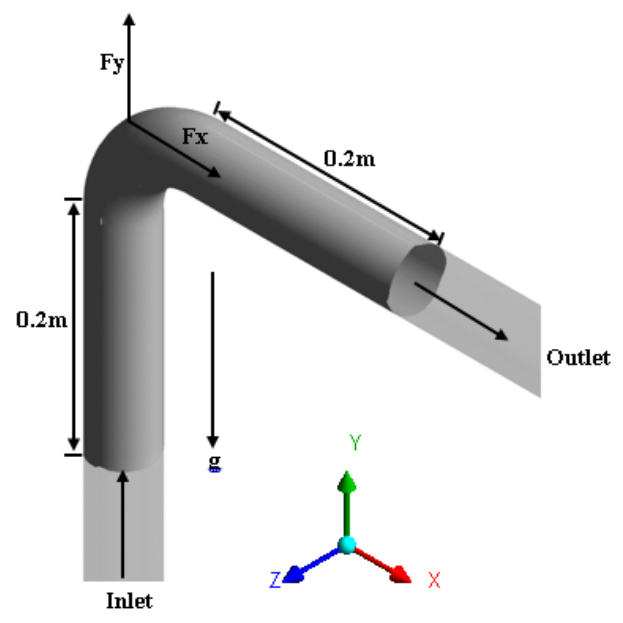

Figure 12: Control Volume around the bend for force calculation 
(a)

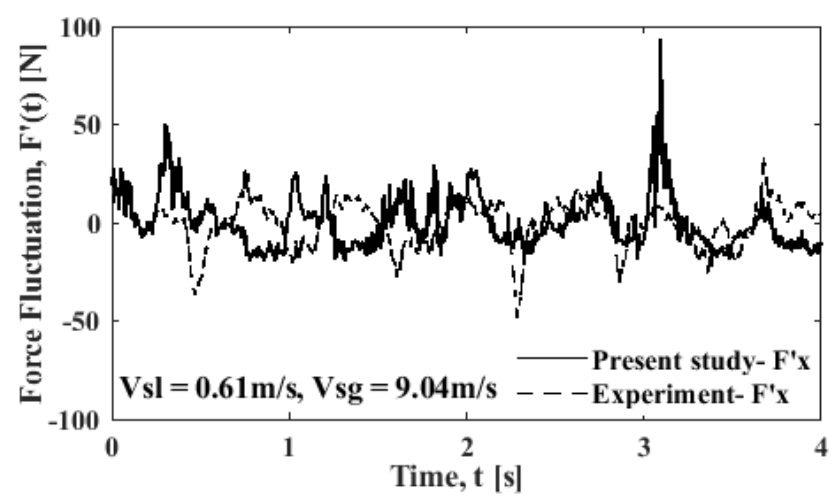

(b)

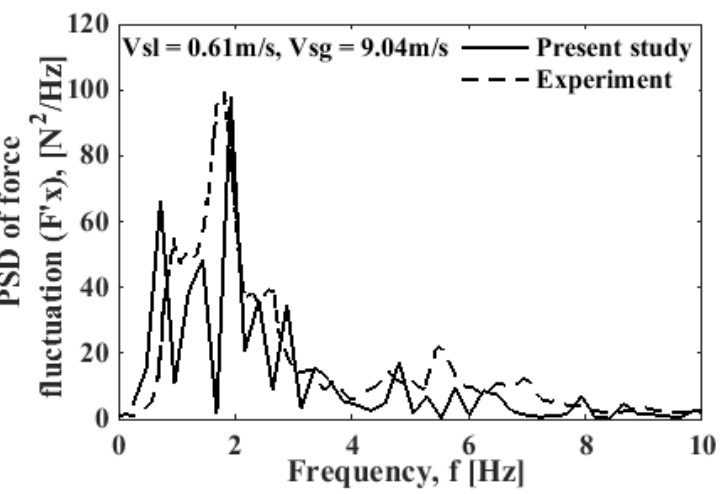

Figure 13: Comparison of present study and experiment (13) for (a) Force fluctuation and (b) PSD for superficial liquid velocity of $0.61 \mathrm{~m} / \mathrm{s}$ and superficial gas velocity of $9.04 \mathrm{~m} / \mathrm{s}$. 
(i)

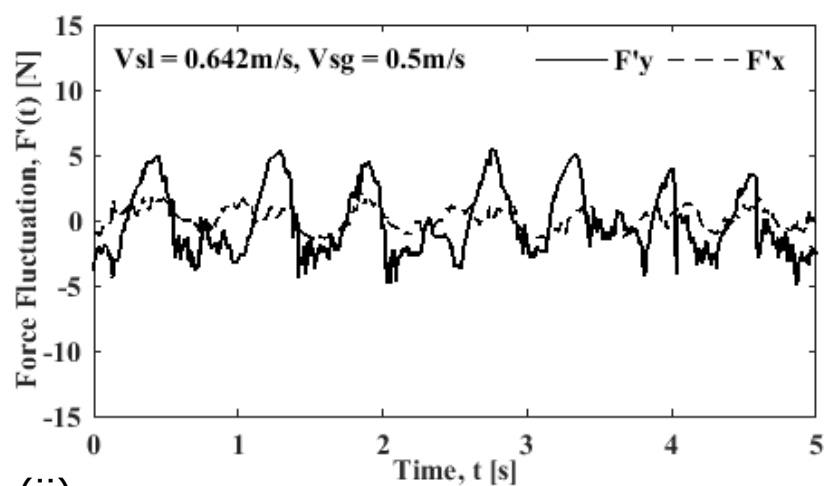

(ii)

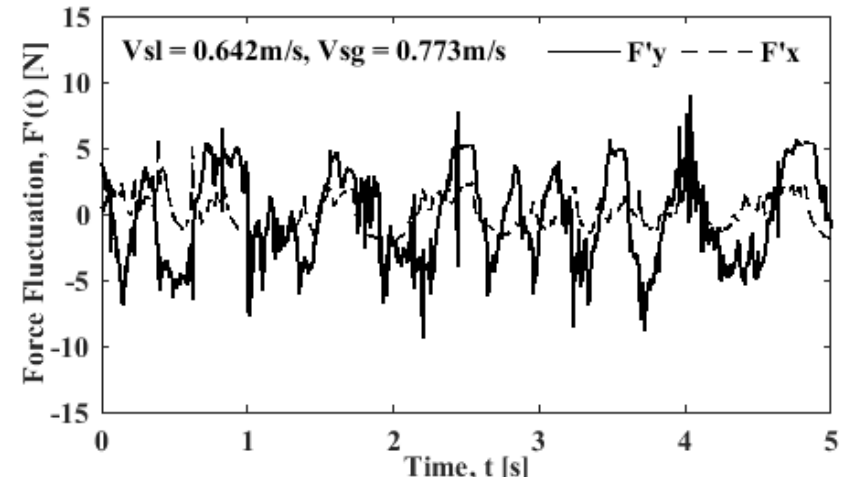

(iii)

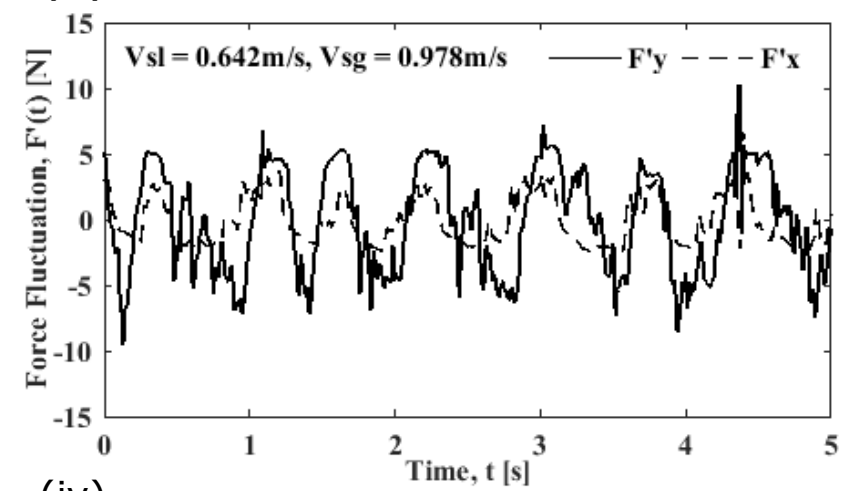

(iv)

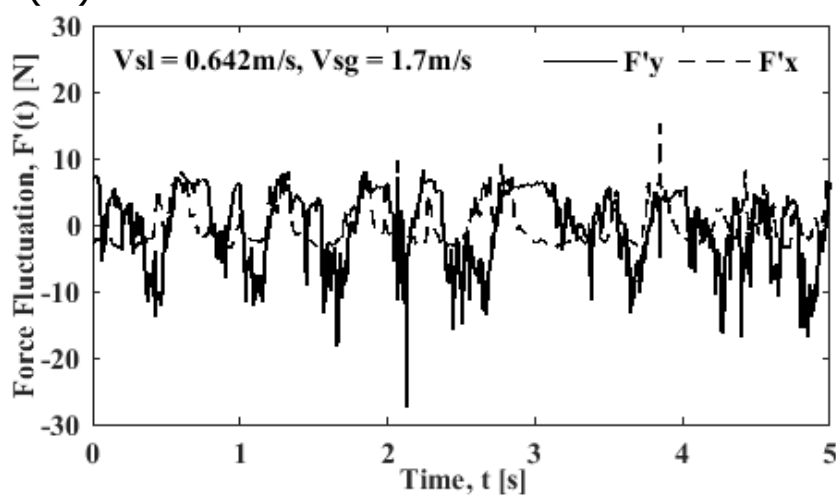

(b)
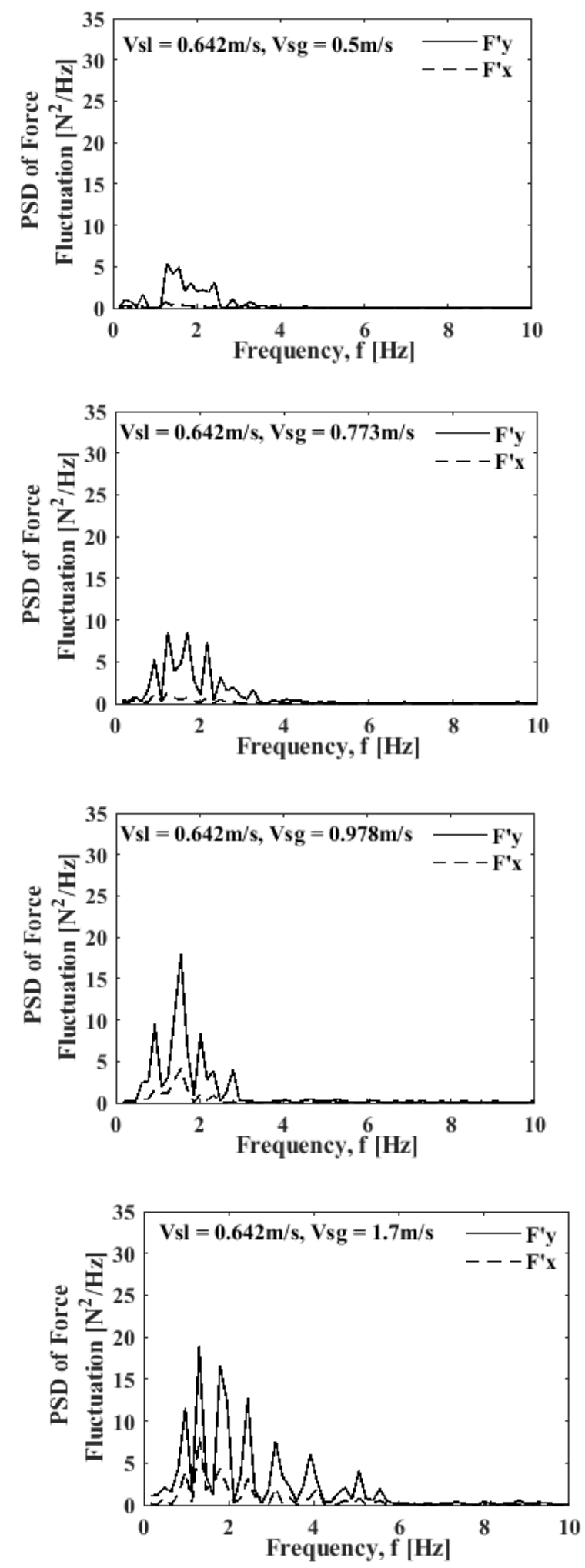
(v)
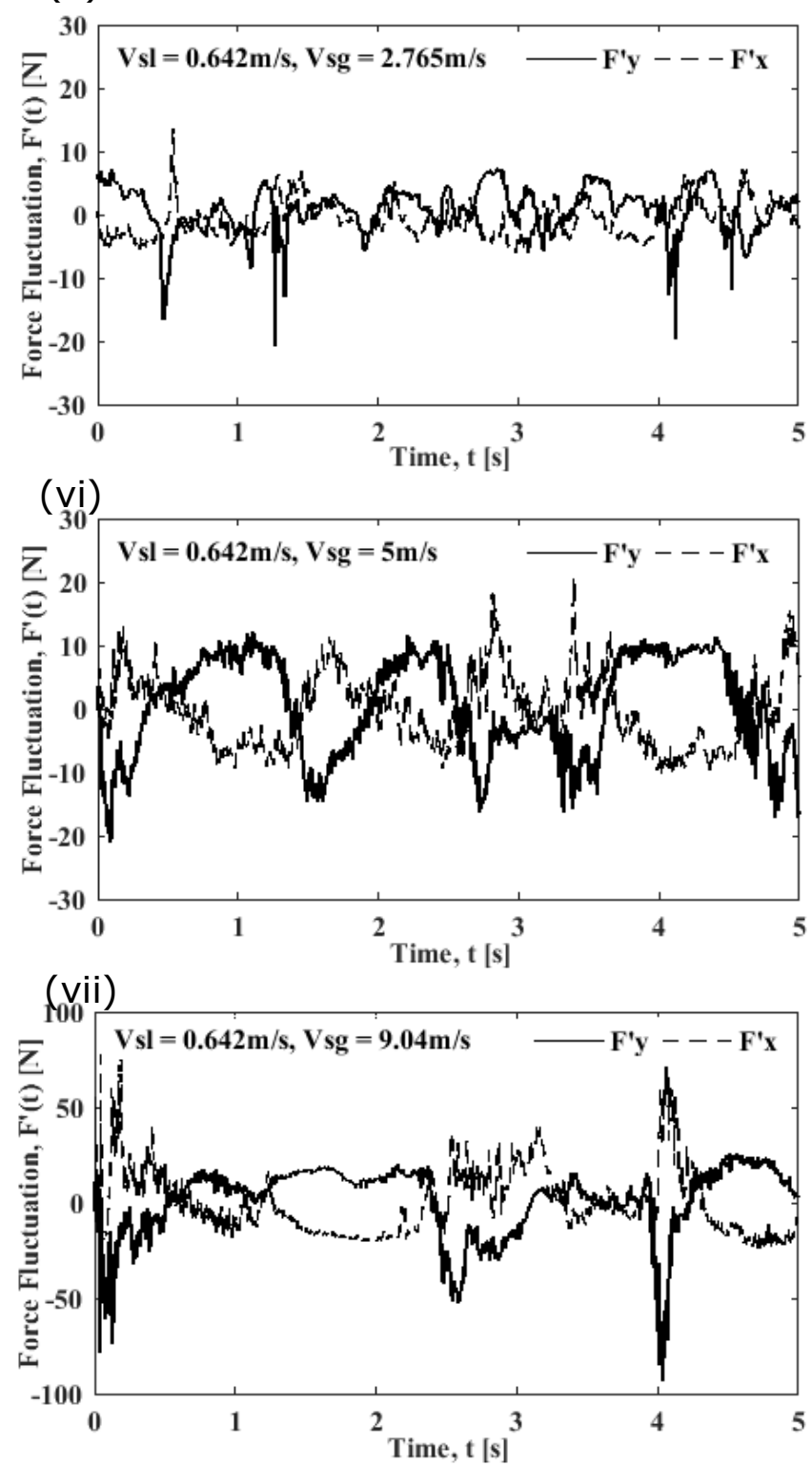

(b)
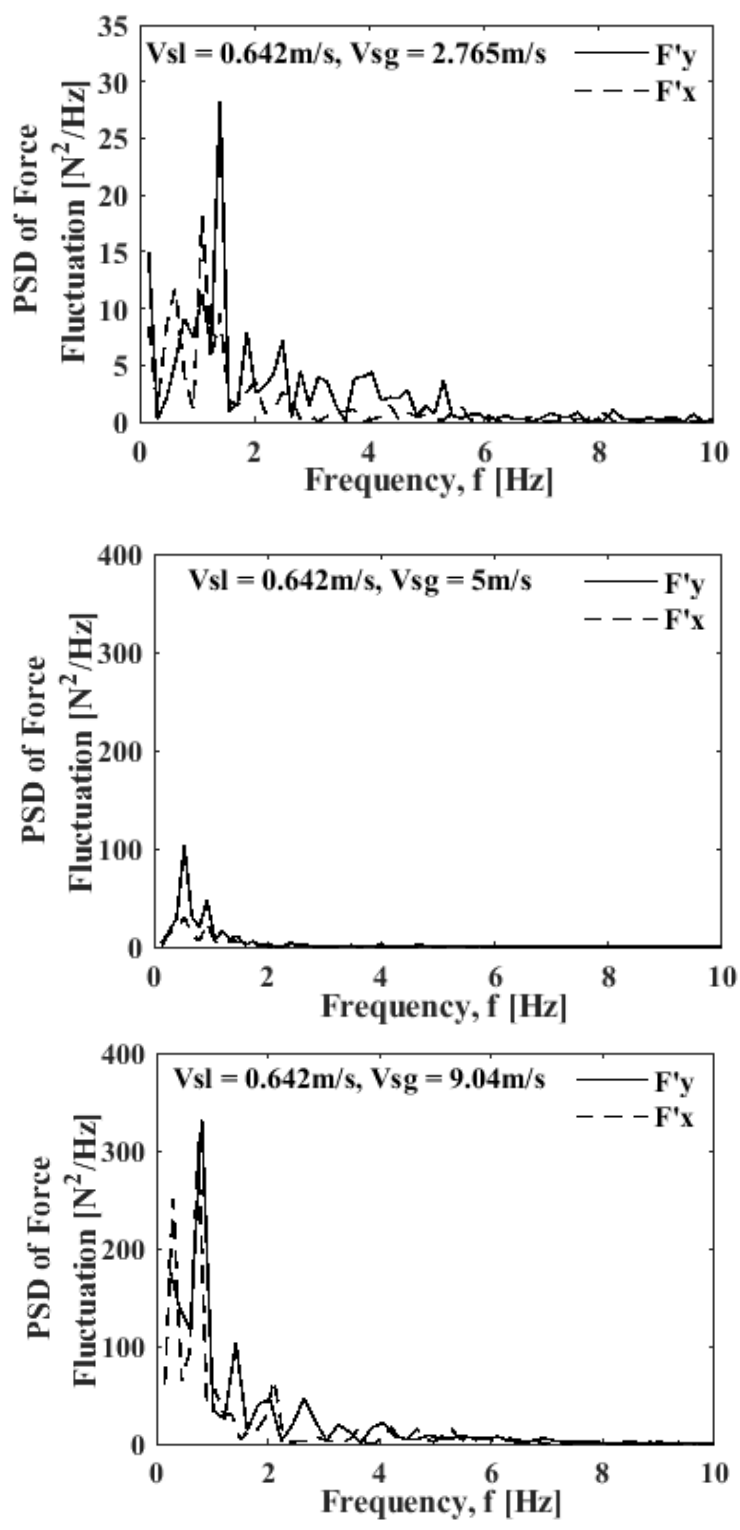

Figure 14: The effect of superficial gas velocity on (a) Force fluctuation and (b) PSD for a fixed superficial liquid velocity fixed at $0.642 \mathrm{~m} / \mathrm{s}$. 
(a)

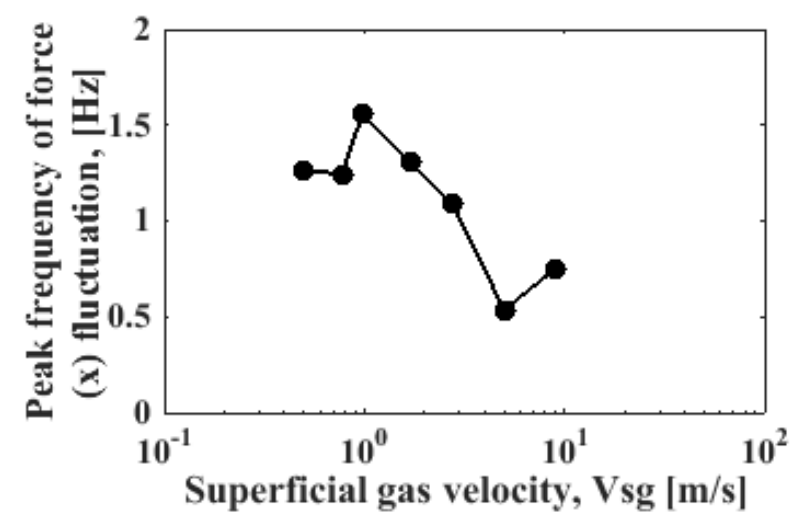

(b)

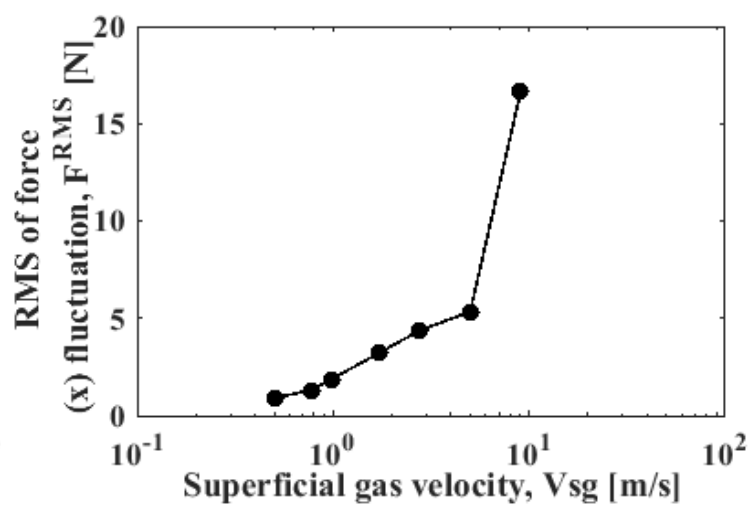

Figure 15: The effect of superficial gas velocity on (a) Peak frequency and (b) RMS values of $x$-component of force fluctuation for a fixed superficial liquid velocity of $0.642 \mathrm{~m} / \mathrm{s}$. 
(a)

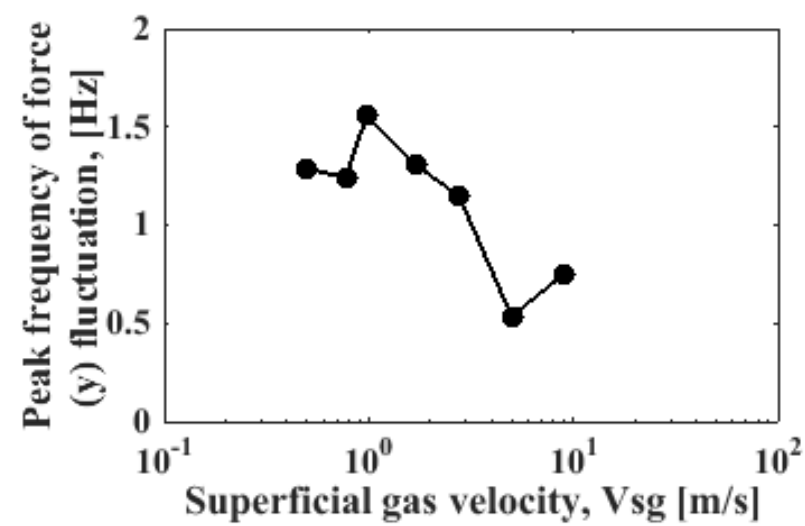

(b)

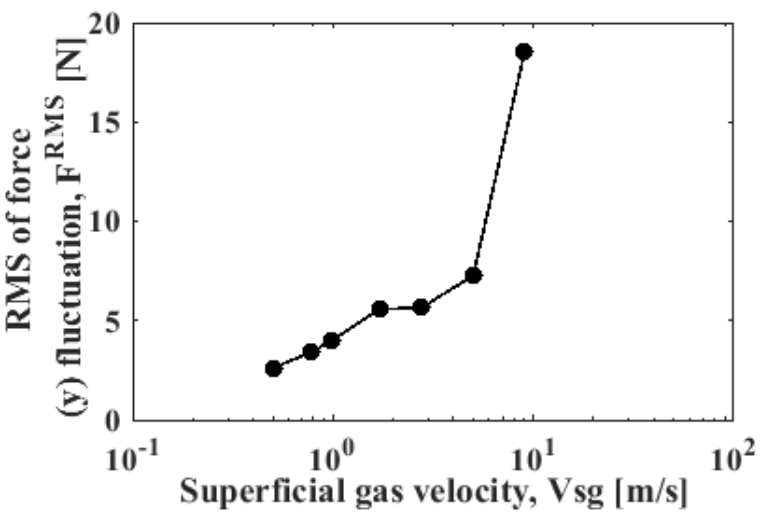

Figure 16: The effect of superficial gas velocity on (a) Peak frequency and (b) RMS values of $y$-component of force fluctuation for a fixed superficial liquid velocity of $0.642 \mathrm{~m} / \mathrm{s}$. 
(i)

(a)

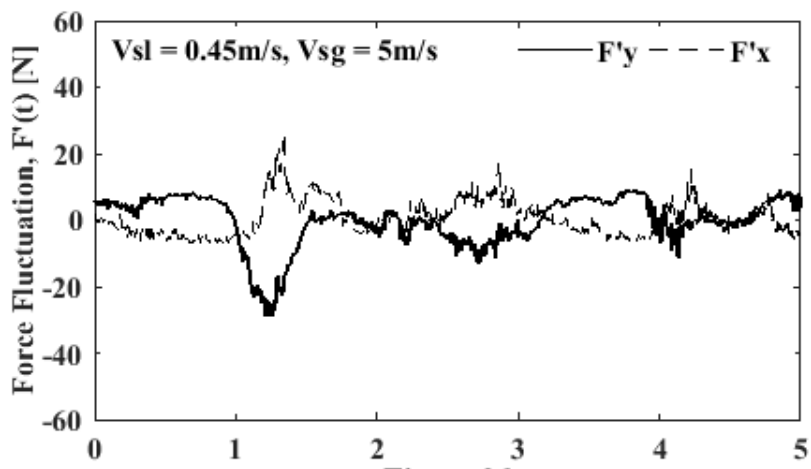

(ii)

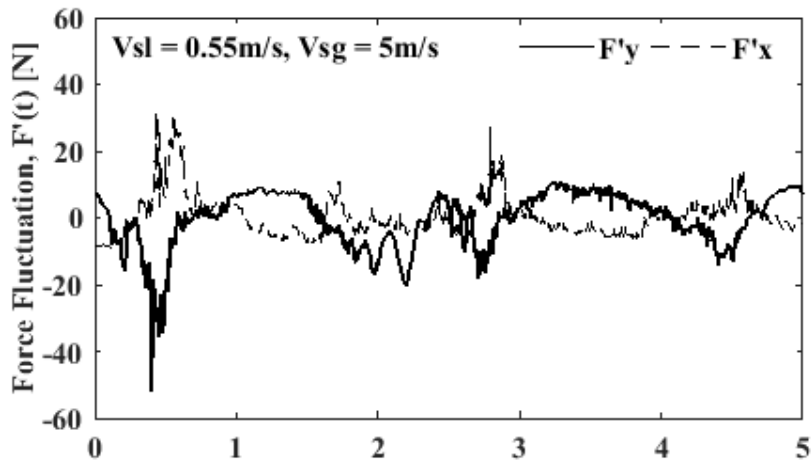

(iii)

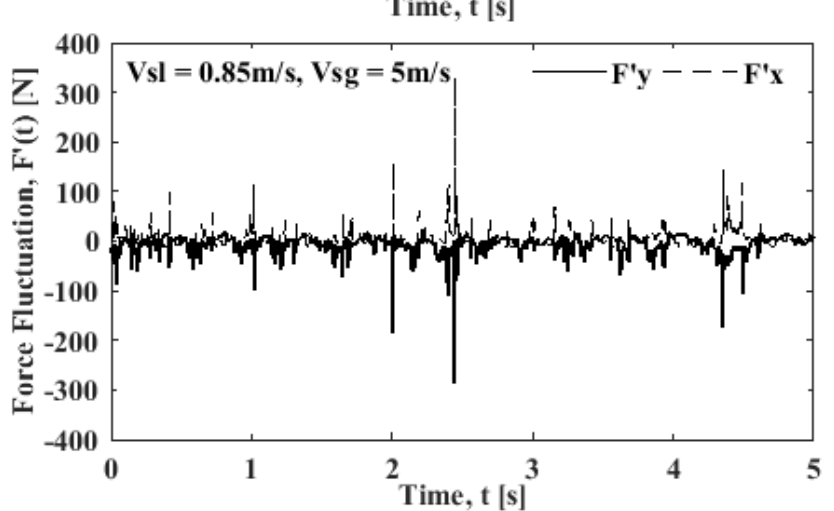

(iv)

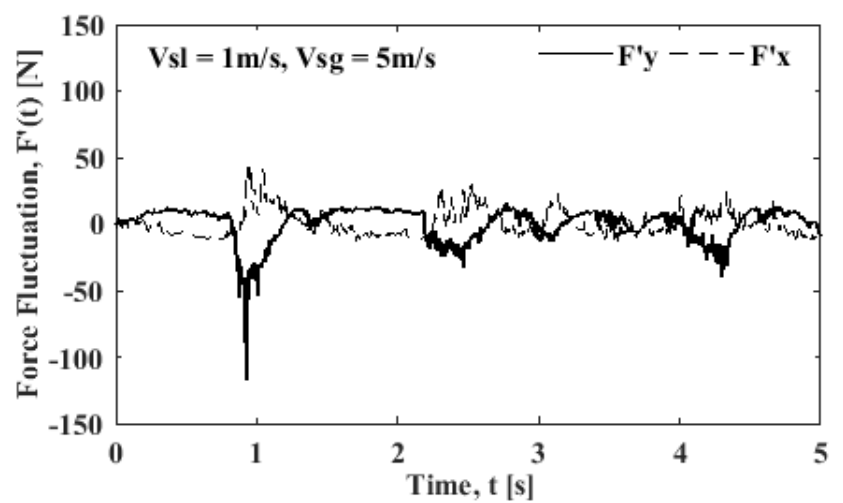

(b)
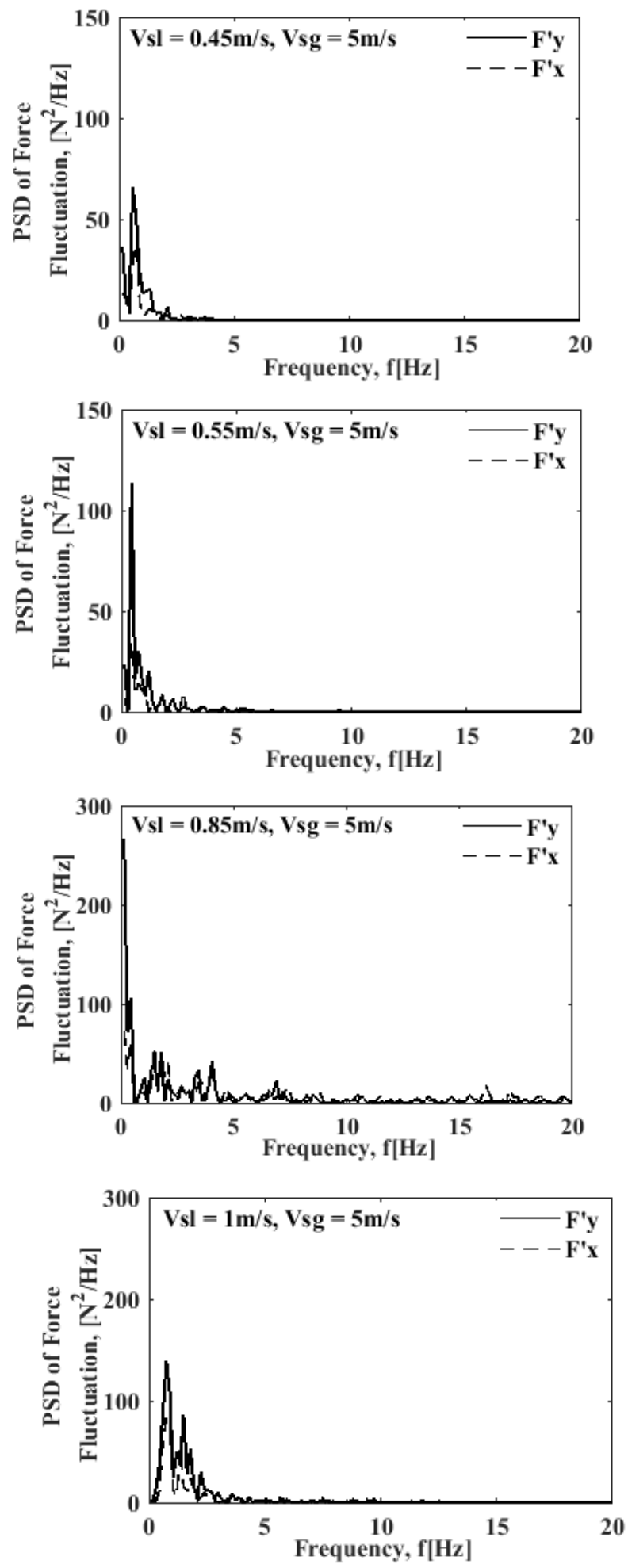
( $v)$
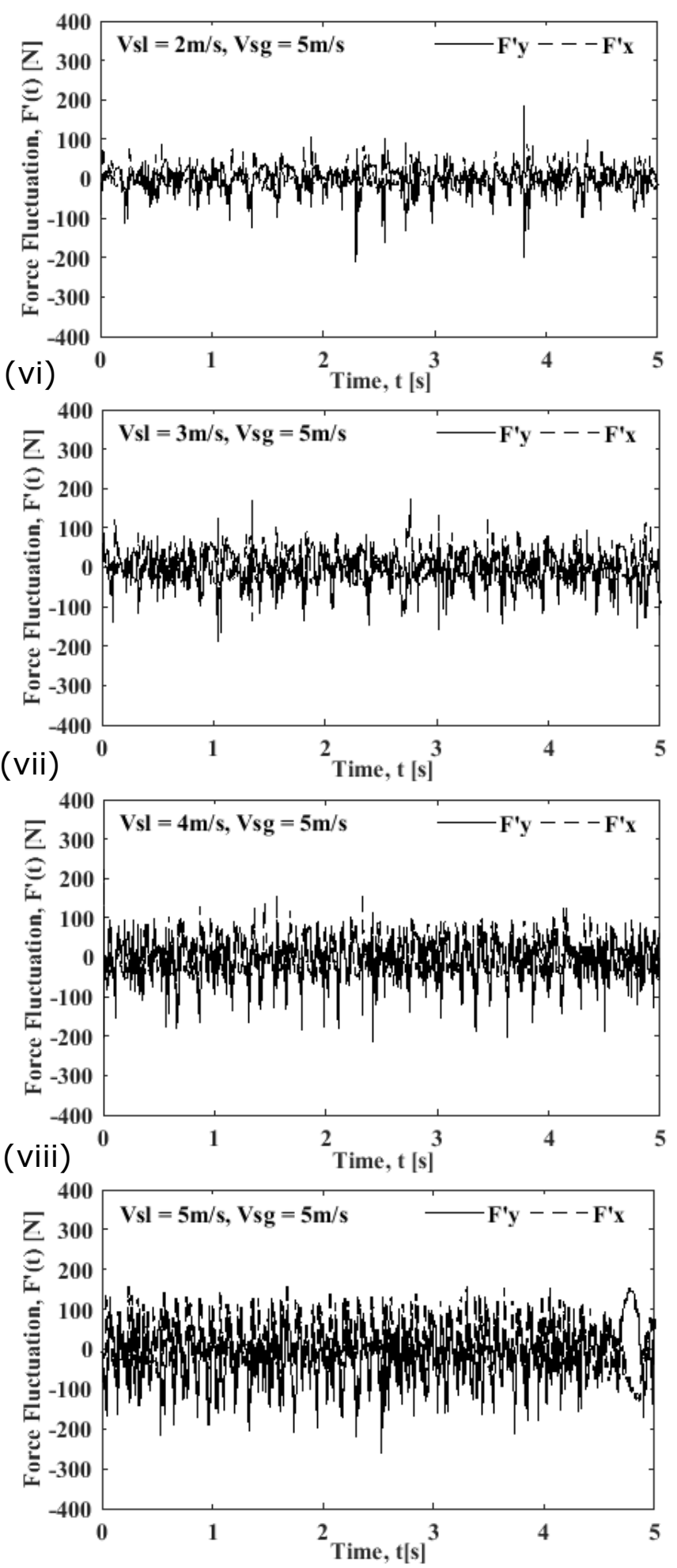

(b)
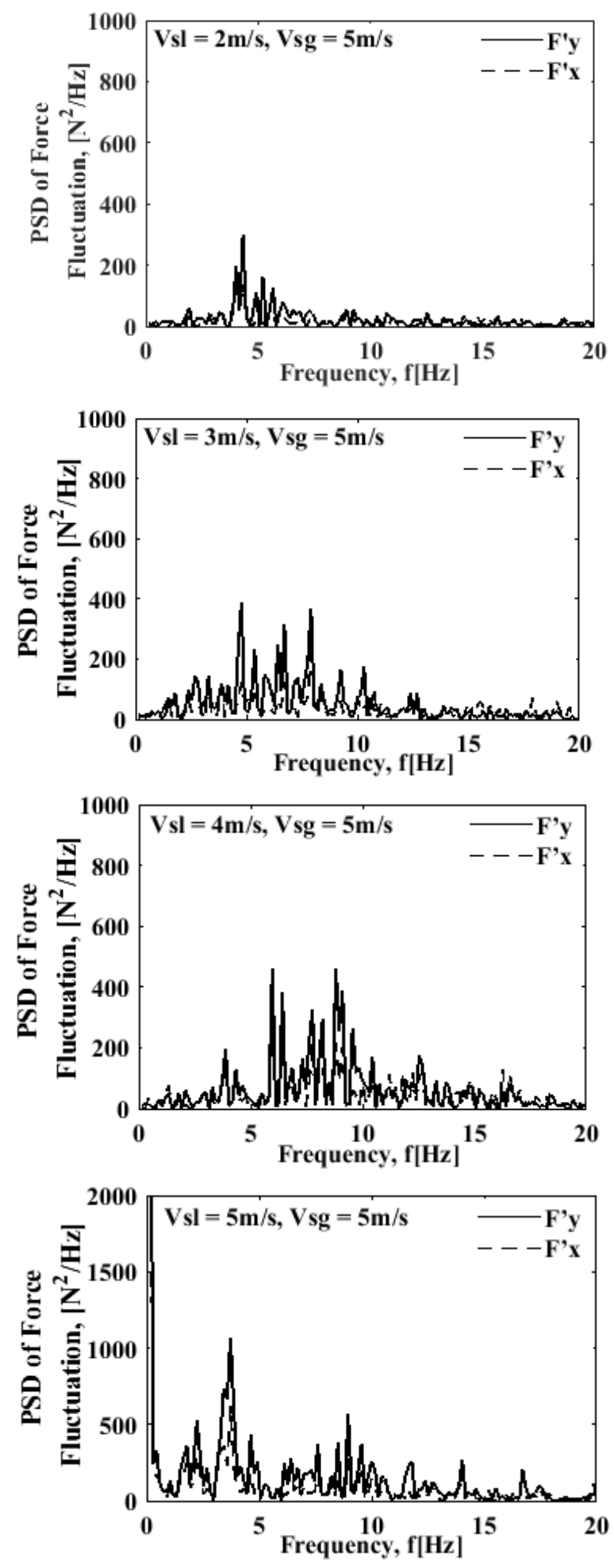

Figure 17: The effect of superficial gas velocity on (a) Force fluctuation and (b) PSD for different superficial liquid velocity for a fixed gas velocity of 5 $\mathrm{m} / \mathrm{s}$.

(b) 
(a)

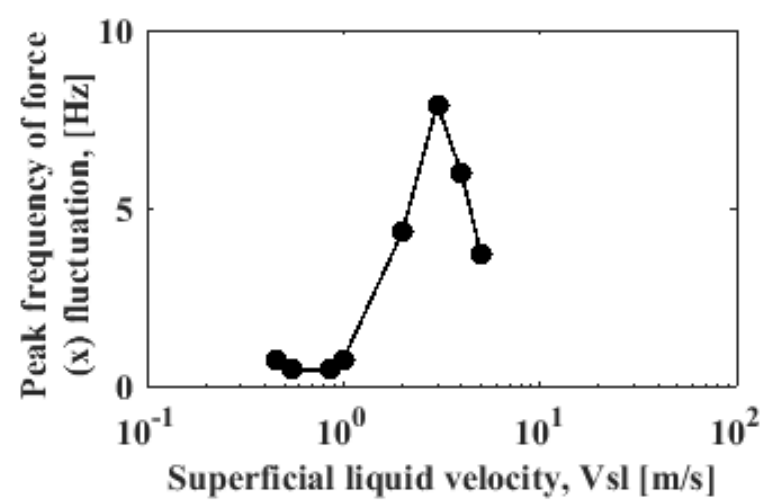

(b)

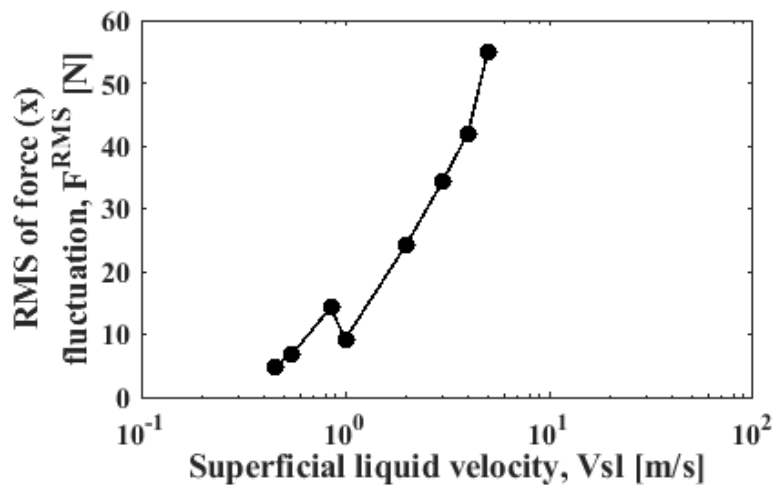

Figure 18: The effect of superficial liquid velocity on (a) peak frequency and (b) RMS values of $x$-component of force fluctuation for a fixed superficial gas velocity of $5 \mathrm{~m} / \mathrm{s}$. 
(a)

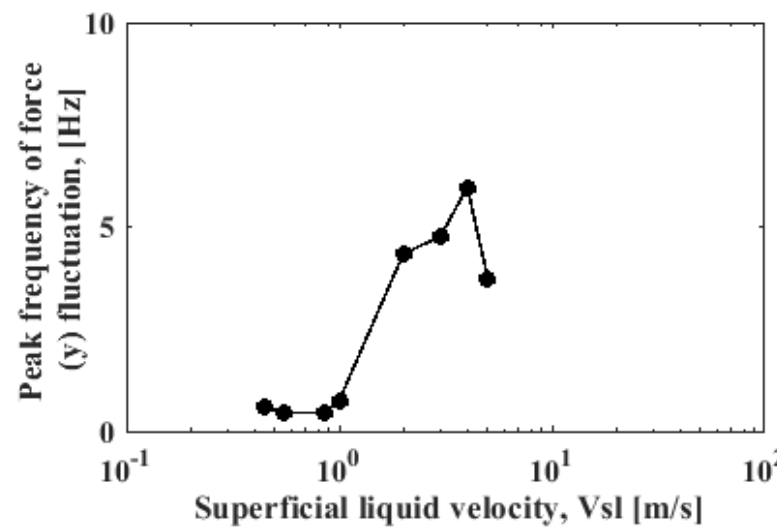

(b)

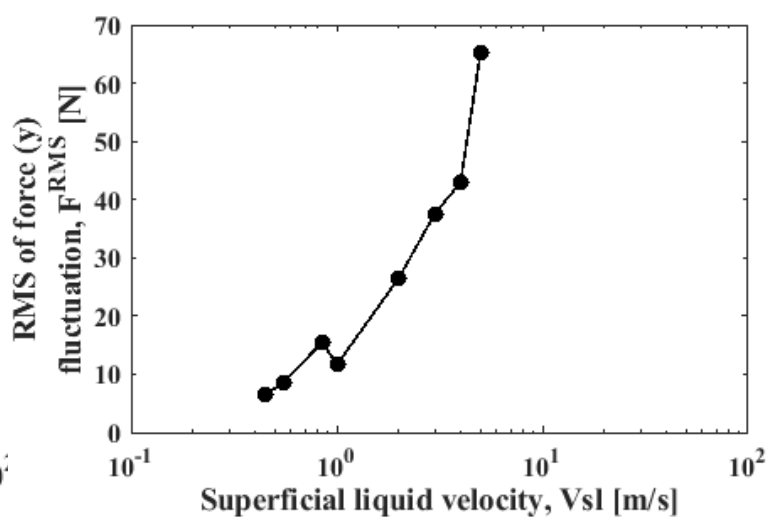

Figure 19: The effect of superficial liquid velocity on (a) peak frequency and (b) RMS values of $y$-component of force fluctuation for a fixed superficial gas velocity of $5 \mathrm{~m} / \mathrm{s}$. 


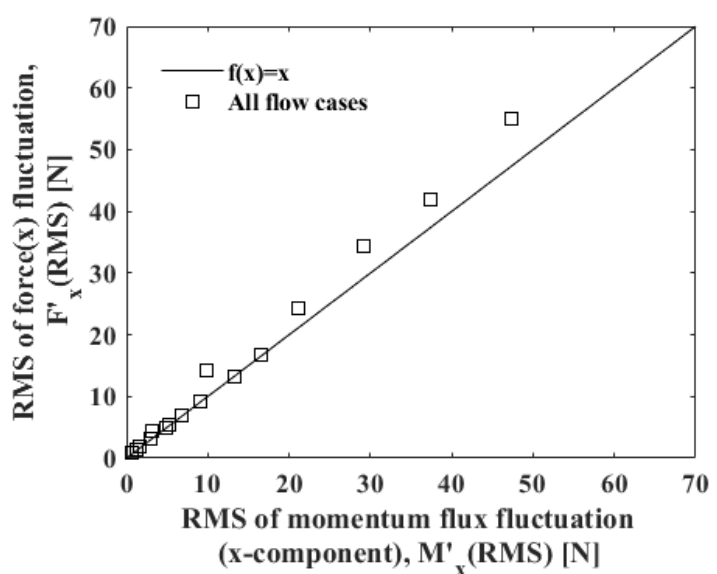

(a)

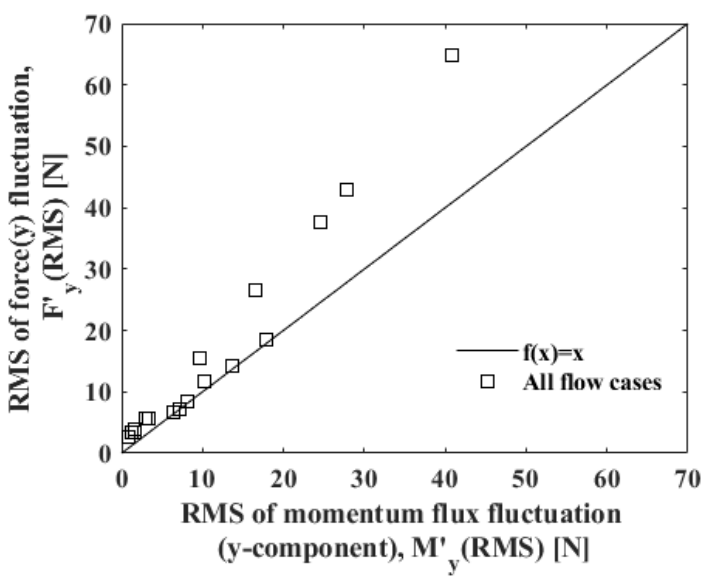

(b)

Figure 20: Comparison of RMS values of momentum fluxes and total forces; (a) $x$-direction (horizontal direction) (b) $y$-direction (vertical direction). Solid line shows perfect correlation.
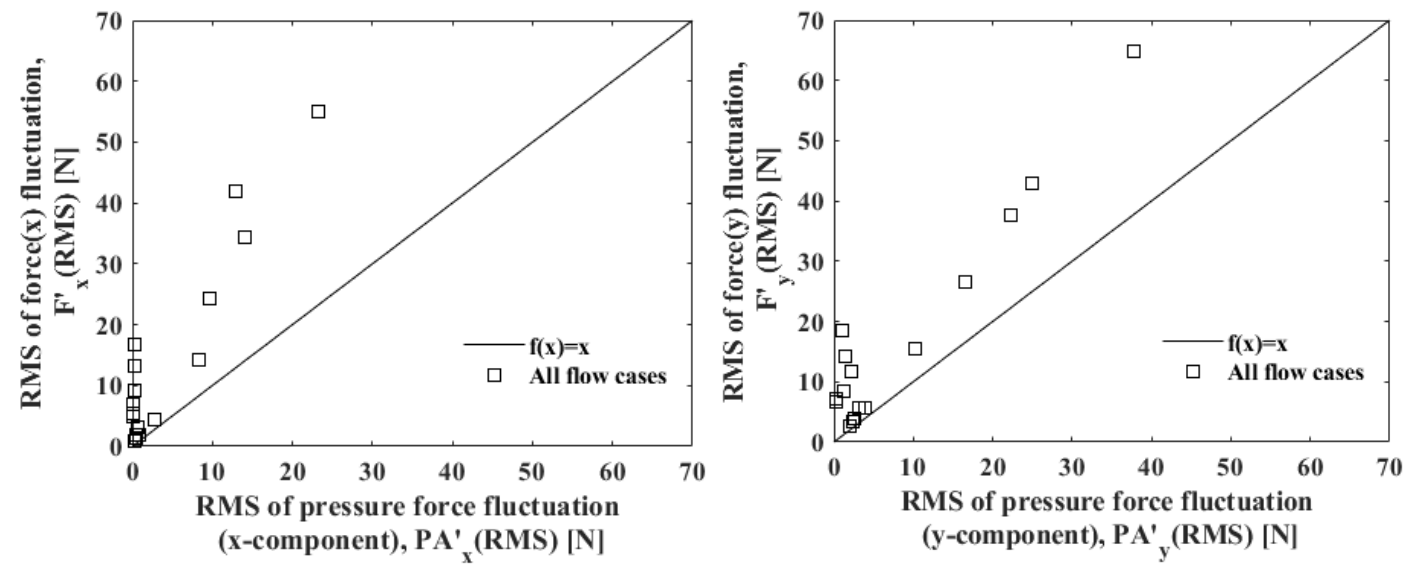

Figure 21: Comparison of RMS values of pressure forces and total forces; (a) $x$-direction (horizontal direction) (b) $y$-direction (vertical direction). Solid line shows perfect correlation. 


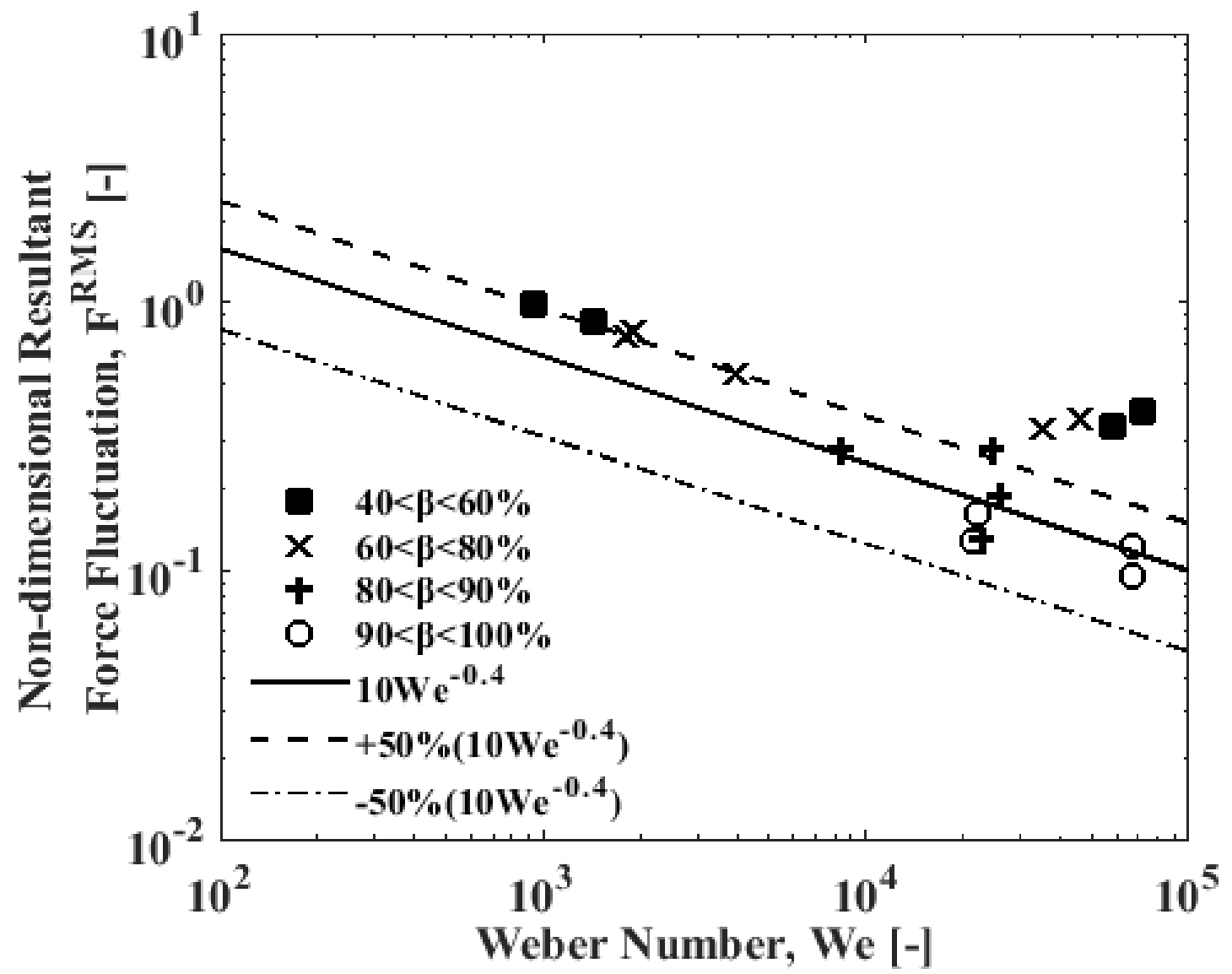

Figure 22: Comparison of RMS values of fluctuating forces with Riverin et al (10) correlation. The 17 cases of simulation data grouped according to volume fraction of gas 